\title{
THE ASSESSMENT OF GROWTH AND DEVELOPMENT IN CHILDREN
}

\author{
BY \\ J. M. TANNER \\ From the Sherrington School of Physiology, St. Thomas's Hospital, London
}

(RECEIVED FOR PUBLICATION JULY 2, 1951)

During the last decade or two, as part of the general application of preventive medicine to human affairs, an increasing interest has been taken in the growth of children. To a large extent this followed the realization on the one hand that malnutrition could cause a retardation of growth in the child, and on the other, that differences in size did actually exist between children belonging to different social classes. From this it was a short step to the assumption that the rate of growth itself afforded an index of the nutrition, or at least of something called the "general condition' of the child; and on this premise, both in relation to groups and to individuals, paediatricians, public health officers and the School Medical Service began to take regular measurements of the children under their care. Having got the measurements it was necessary to have something with which to compare them, and standard figures from supposedly good samples of supposedly healthy children were soon forthcoming. The Baldwin-Wood tables, for example, a 1923 revision of figures first published in 1910, were widely used for a time and found their way into many textbooks of paediatrics. Alongside the salutary results of all this activity, two bad effects were clearly to be seen. When standards were first published what is implied by "the spread of the normal ${ }^{\prime}$ and 'the limits of the normal zone' was not at all generally understood. Anxious parents, consulting the oracular weighing-machine, plagued their practitioners with complaints of their children being five pounds under- or over-weight for their height and age, and this despite both mother and father being miracles of thinness or rotundity. Also it began to be quite uncritically assumed that the faster you grew the better it was, and since the more you ate the faster you grew - particularly in weightan era of stuffing babies and children regardless of all psychiatric or humanitarian principles began.
Only recently have any voices been raised against this trend, but there are signs that these are now making themselves heard, and animal evidence on feeding and longevity (Ball, Barnes and Visscher, 1947), though probably not strictly relevant, will doubtless help to redress the balance.

Meanwhile, more and more standards have been published, most using height and weight combined with other anthropometric measurements and some, in addition, assessments of maturity by hand, radiograph or bodily appearance. The situation has grown somewhat confusing and a general clarification would seem useful at the present juncture. It is the aim of this paper, therefore, to give a coherent account of the standards in use and the principles on which they are constructed, using language as non-technical as is possible without shirking the issues involved. It is foolish to pretend that any of the methods so far proposed are ideal or even very satisfactory, and the reader must not imagine that at the end he will emerge with a finally chosen foolproof, automatic system for use on all occasions: it is hoped, rather, that he may be brought to a clearer conception of the methods at present available, the foundations on which each is based, and the uses to which each can and cannot be put. A new arrangement both for graphing and reporting growth progress is suggested in Figs. 5 and 8 , but the suggestion is a tentative one requiring practical test, and the arrangement is certainly not as suitable for some periods of growth as for others: at puberty, for example, it seems likely that some slight complications will have to be introduced if the precision of the standards is to be maintained.

The paper is divided into sections: the meaning of abnormal; percentiles versus standard deviations; distance versus velocity standards; distance standards available (measurements considered singly); use of distance standards for assessing 
velocity; multiple measurement distance standards; a suggested form for combined distance, velocity and standard-score difference standards; standards for maturity; conclusion.

\section{The Meaning of 'Abnormal'}

The point of any standard of whatever sort is to enable the physician, nurse or whoever it may be to give at least a tentative answer to the question, "Is this child abnormal ?' If the answer is no, the anxious mother is reassured; if yes, further steps are taken to eradicate or minimize the abnormality, and to remove, if possible, its source. But this question is not quite as simple as may appear at first sight and we must begin by getting clear in our minds just what the question implies and just what sort of an answer it is possible to give.

We shall consider in this section only one single measurement; let us say of stature. If we measure a very large number of 6-year-old children, all healthy so far as we know, we shall find a few short ones, a few tall ones and a lot of middling height. If we plot a graph of the number of children along the $y$ axis against stature along the $x$ axis we will have a series of points, and if we join these by a smoothed curve we shall have the frequency distribution curve illustrated in Fig. 1A and 1B; this is a Gaussian or normal curve of distribution. In Fig. 1A a series of vertical lines have been put in, delimiting the percentiles of the distribution; by this is meant that $1 \%$ of the population are smaller than the stature given by the vertical line marked 1, $2.5 \%$ are smaller than the stature given at the line $2 \cdot 5$, and so on. For this sort of distribution curve the mean stature of the group and the 50th percentile coincide; just half the population are below the mean stature and half above it. Now if we have a 6-year-old child $M$ we can immediately compare his stature to that of this standardizing population by seeing which percentile on the figure he lies nearest. If his stature is the same as that of the 95th percentile we can say that only $5 \%$ of healthy children of this age are taller than $M$. If it lies at the 99th percentile, only $1 \%$ of healthy children are taller. If $\mathbf{M}$ is as tall as this then obviously the suspicion is aroused that he is ' abnormally' tall; in other words, that he is not really a member of this healthy population to which he is being compared, but of another, unhealthy population.

Now suppose we have a second group of children, all of whom have acidophil adenomata of the pituitary, mid-brain tumours and so forth. This is the abnormal population, and on average its members will be taller than the members of the normal population. But the two populations may overlap in distribution, and we then get the situation hypothetically illustrated in Fig. 2; in general the unhealthy population is likely to be a mixture coming from various causes of ill-health with varying effects, producing a frequency distribution which is not Gaussian and has a large scatter. We can now return to child $M$, stature at the 99th percentile, with a clear idea of what we mean by affirming or denying that he is abnormal. Since the populations overlap in this region it is not possible to say with certainty that $M$ belongs to one or to the other. All we can state is the probability of his belonging to one or the other, and this probability we can state precisely if we know the distributions of the two populations. In practice we usually do not know the distribution of the unhealthy population and we lay down arbitrary 'limits of normality'. It is essential to recognize that these are arbitrary, and to understand what they imply. Suppose we take the stand that anybody over the 95th percentile shall be called ' abnormally tall'. Most, perhaps, of the actually abnormally tall would be picked up by this procedure, but at the expense of including in this category five out of every 100 normal children. If we adopt the 99th percentile as the limit, then we may pick up fewer real abnormals, but we shall only call one normal person in every 100 abnormal. The limits of normality we should adopt must depend on the use to which they are going to be put; if the result of being classified as abnormal was immediate and serious operation, we should have to put the limit even beyond the 99th percentile, to ensure we operated on very few normals, but if stature is being used as a first screening test for suspected malnutrition, say, with a result nothing more drastic than a visit to the specialist and some extra milk in the mornings, our limits could be much lower, perhaps even at the 80th, or in this particular example, its lower equivalent the 20th, percentile. This sort of problem, though stated here in somewhat academic terms, arises acutely sometimes in paediatric practice, as, for example, in whether or not to explore for a possible tumour in a girl who begins to menstruate somewhat earlier than usual.

Percentiles versus Standard Deviations

Standards of growth in current use employ either the percentile division outlined above or else a division of the healthy population by standard deviations* (e.g. Sontag and Reynolds, 1945). In

\footnotetext{
- The standard deviation $(\sigma)$ is a measure of the spread of a frequency distribution. It is particularly appropriate to Gaussian distributions, in which the correspondence of various multiples of $\sigma$ to various percentiles can be seen from Figs. $1 A$ and $1 B$. It is estimated from a sample of readings as the square root of the sum of the squares of the deviations of the readings from their mean divided by one less than the number of readings.
} 

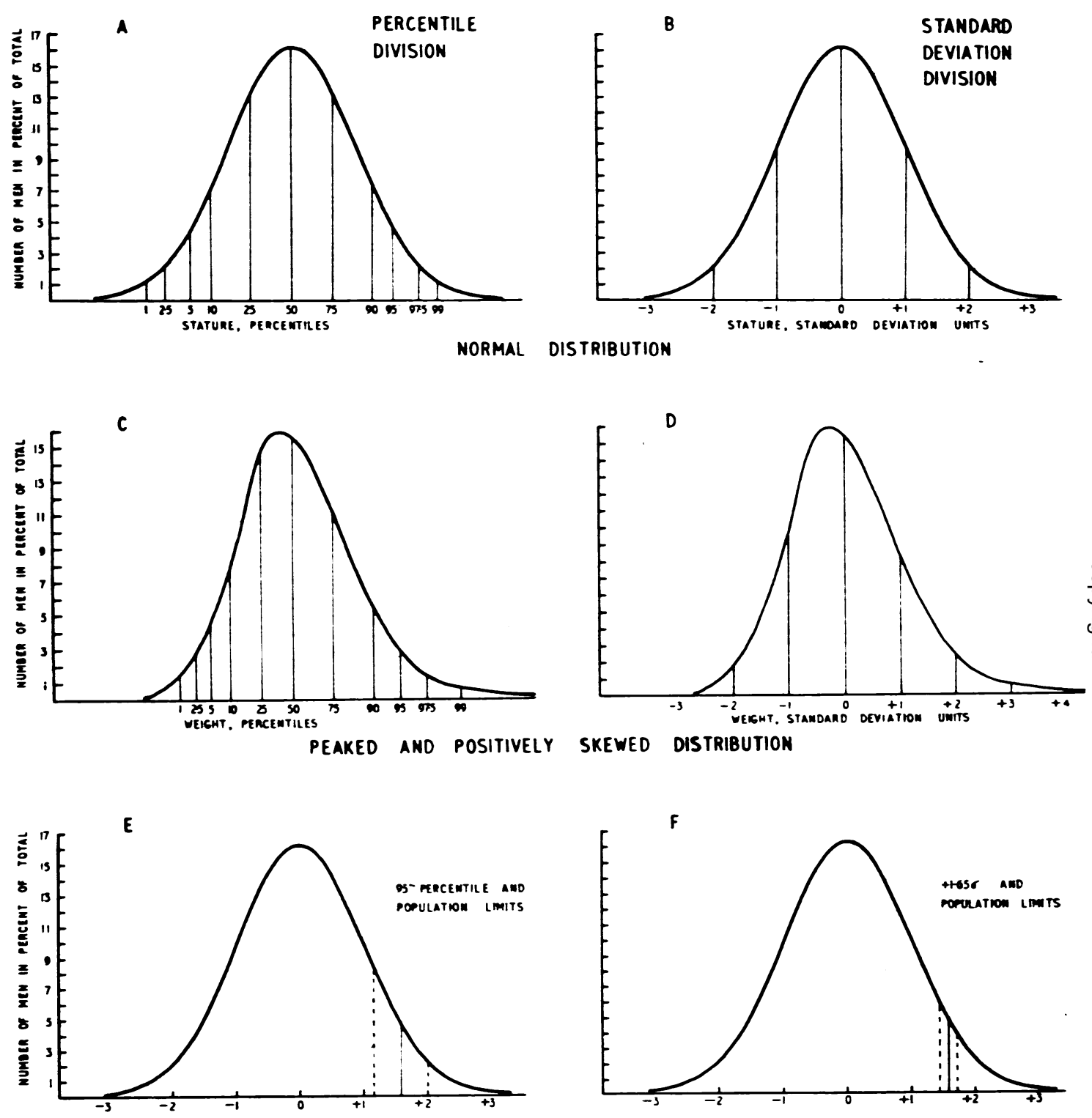

95\%. POPULATION LIMITS FOR UPPER 95- PERCENTILE AND +1.65 6 COMPARED.

SAMPLE SIZE 100, 6 UNITY, NORMAL DISTRIBUTION

Fig. 1.-To illustrate the relation of percentile and standard deviation divisions of $A$ and $B$ a normally distributed population, $C$ and $D$ a peaked and positively skewed distribution. $E$ and $F$ show the sampling limits of the upper $95 \%$ point in a normal distribution. 
the latter case, the standard deviations are used essentially as percentiles (see Fig. 1); the given child's stature is found to be greater than the mean by a certain figure and this figure is so many, say, $2 \cdot 3$, standard deviations $(\sigma)$. By reference to a table of the Gaussian curve it is found that only $1 \%$ of the

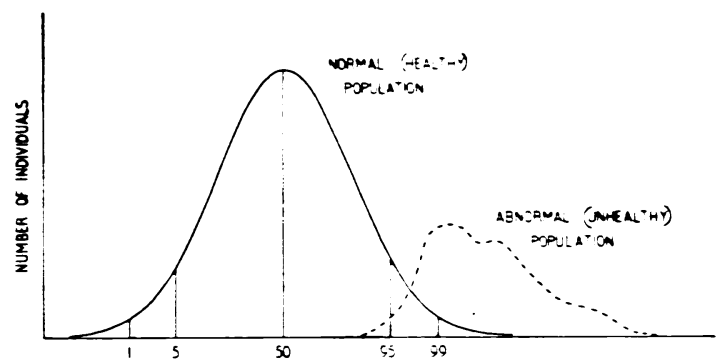

Fig. 2.-Possible overlap of a healthy and unhealthy population (hypothetical).

population are taller than $2 \cdot 3 \sigma$ above the mean, and the interpretation and the laying down of limits proceeds as before. In other words, provided the population distribution is Gaussian, as in Fig. 1A and $\mathrm{B},+2 \cdot 3 \sigma$ corresponds to the 99 th percentile, $-2 \cdot 3 \sigma$ to the first percentile, $+1 \cdot 65 \sigma$ to the 95 th percentile, $-1.65 \sigma$ to the fifth percentile, and $\pm 0.67 \sigma$ to the 25 th and 75 th percentiles.

This reasoning, however, breaks down if the distribution of the healthy population for some measurement is not Gaussian, but skewed, as in Fig. $1 C$ and D. Here a distribution curve similar to that usually found for body weight is given; it is not Gaussian, but has a higher peak and a longer tail out to the right. (Weight, it may be noted, is the most highly skewed of all the commonly used measurements with the exception of subcutaneous tissue thickness; most length measurements have Gaussian distributions, and breadths, depths and some circumferences tend to be a little skewed in the same direction as weight.) In such a skewed distribution percentiles can still be drawn in, as in Fig. 1C, though the 50th percentile no longer corresponds either to the peak of the curve or to the value of the arithmetic mean. But as can be seen from Fig. 1D the standard deviations no longer correspond to the same percentiles as for the Gaussian curve. We can no longer say that a child of $+2 \cdot 3 \sigma$ is exceeded in weight by $1 \%$ of the healthy population; clearly he is exceeded by more. Thus the use of standard deviation divisions is fraught with errors of interpretation unless the population distribution is Gaussian.

There are, however, two advantages in the use of standard deviations rather than percentiles. First, there is the relatively unimportant one that the presentation of standard data is simplified; all that need be given is the mean and the standard deviation, the table of the Gaussian curve for passing from standard deviations to percentiles being in any book of elementary statistics. Secondly, there is a more telling advantage of a biometrical nature. All the standard data published are data on samples of healthy children, not the complete measurements of every healthy child in the country (let alone the extra ones needed by the mathematicians to make their population infinite). Most of the samples consist of a few hundred children at each age; the published standards, however, are for the whole healthy population. We find the 95th percentile for our sample, and from this estimate the 95th percentile for our whole population. The estimate is subject to a certain amount of error; all we can say with confidence is that the population 95th percentile lies between the two limits illustrated in Fig. 1F by the two vertical interrupted lines (unless we have been so unlucky as to have struck a sample which would only occur less than five times in 100 , in which case the population value will lie actually outside these limits). In the same way we can calculate the standard deviation from our sample and estimate the 95th percentile of the population as 1.65 standard deviations, but in this case the limits between which our population figure is fairly sure to lie are much narrower, provided the distribution is Gaussian. This is illustrated in Fig. 1F; compare the position of the vertical interrupted lines with Fig. 1E. Looked at another way, it requires more children in the standardizing sample to estimate the percentiles for the population to a given degree of accuracy than it does to estimate the standard deviation. In fact, it needs, in a Gaussian distribution, just four times as many to estimate the 95th percentile with the same accuracy as the $1.65 \sigma$ level, and 14 times as many to estimate the 97.5 percentile with the same accuracy as its corresponding $2 \sigma$ level.

The question can be summed up thus: if the distribution of the measurement is Gaussian or very near it, then standard deviation divisions and limits of normality are preferable. But if the distribution is non-Gaussian, then percentile division has to be used since the standard deviation method will not locate the point required; in technical language, it is biased. Just where the degree of skewness in the distribution balances the loss of precision due to the larger sampling error is a nice point and one not practically clear (a small bias may be permissible if a great gain in precision accompanies it). Consequently it is not possible to choose flatly between the two methods at present; perhaps the most 
rewarding approach to skewed distributions ultimately may be to use transformations (e.g. log weight or index weight $0 \cdot 8$ instead of weight) which will turn them into Gaussian ones, but at present too little is known about most anthropometric distributions for this to be practicable. An equivalent and practically simpler approach would be to tabulate the standard deviations and values corresponding, in the various skewed anthropometric distributions, to the first, fifth, 50th, 95th and 99th percentiles.

\section{Distance versus Velocity Standards}

We have now discussed what we mean by abnormal, and how we judge whether a given child reaches or does not reach our arbitrary limits of normality. We must next consider what sort of standards exist for judging children, and what advantages and disadvantages each possesses. Let us take first the measurement of one single dimension only, such as stature. There are four questions we may ask about a given child $\mathbf{M}$. A. Is $\mathbf{M}$ abnormally tall or short at a particular age, say 6 ? B. Did $M$ grow abnormally fast or slowly during a particular period, say 5 to 6? C. Was M's deceleration from the period 5 to 6 years to the period 6 to 7 years abnormally large or small ? D. Was M's curve of growth in stature abnormal in any respect from birth to age 7 or to adulthood?

Growth is a form of motion, and question $A$ seeks to characterize the motion by the distance achieved in a certain time, $B$ by the velocity over a certain period, $C$ by acceleration and $D$ by a more complex consideration of the whole curve of motion from birth onwards. Question D is the most searching, but we may dismiss it at once, for it will be many decades before any acceptable standards for individual birth-to-maturity curves are available. Question C is almost equally impracticable at present and we are left with a choice between distance and velocity standards, answering questions $A$ and $B$ respectively.

Velocity Standards. Which question is the most rewarding to answer varies somewhat with circumstances, but other things being equal, it seems to me likely that the testing of velocity, or increments of growth, is to be preferred. Pathogenic factors would usually affect rate of growth directly and distance achieved only after the altered rate has had time to produce its result, so that one would expect earlier diagnoses of abnormality to be made by reference to rate. In this opinion also $I$ am in the best possible company, for Shuttleworth has advocated using increments since 1934. All the same, velocity standards have never been seriously used up to the present and indeed very few usable standards exist. The reason for this appears to be threefold. First, the consultant paediatrician may only see a child once and, it is said, may never know anything about the child's increment. This is an argument which carries no weight in relation to the school medical officer and the general practitioner who have or could often obtain measurement records extending over several years, and for these to be made available to the consultant is a not insoluble administrative problem. Second, the determination of annual increment involves two measuring errors instead of one, and records are usable only if the measurements are made with reasonable care and accuracy and without looking at the card first to see what the previous figures were. Third, and by far the most important, velocity standards are extremely hard to come by, because they must give not only the average increments but also their variability, and to do this involves measuring children not just once but twice or more at yearly or shorter intervals. Velocity standards, in other words, must come from what students of child growth call longitudinal rather then crosssectional growth studies, the former term referring to the measurement of the same children at different ages, the latter to the measurement of different children at different ages. Longitudinal studies carried over several years involve a good deal of money, administrative labour and the ability to wait a long time for results. Fleming's study (1933), confined to stature and head measurements, is the only one so far carried to the stage of publication in this country, though three studies are in progress at present, one at the Institute of Social Medicine at Oxford, another at the National Children's Home, Harpenden, under the joint sponsorship of the Ministry of Health and the Sherrington School of Physiology of St. Thomas's Hospital, London, and a third at the Institutes of Child Health and Education of London University. We are at present, therefore, dependent on the United States for this type of data: a short description of the major studies completed or in progress there will be found elsewhere (Tanner, 1949a), as well as a more extended one if required (Tanner, 1948). Even after the longitudinal study has been made there has been a further difficulty. Due to some children inevitably leaving in midcourse, the investigation always produces in the end a mixture of longitudinal and cross-sectional data, and there has been considerable confusion as to how proper velocity standards can be obtained from such records. Techniques have recently become available, however, as described previously (Tanner, 1951a).

There are four sets of data which seem useful for velocity standards. Robinow (1942) has given mean increments and standard deviations from birth to 
age 6 for height and weight on approximately 100 children from upper middle class homes in Ohio; they were studied at the Fels Institute and the increments are reported in three-monthly periods to one year and six-monthly thereafter, the sexes being combined. Simmons and Todd (1938) have given yearly increments with standard deviations for height and weight from 3 months to 13 years, with the sexes separate. The annual increments are based on numbers which vary from about 50 to 150 of each sex for the various incremental periods, and the children are also mostly from upper middle class homes in Ohio. Palmer and his associates (Palmer and Reed, 1935; Palmer, Kawakami and Reed, 1937) have published annual increment figures for height and weight from age 6 to 14 for boys and girls separately, the data coming from the U.S. Public Health Service Survey of Hagerstown in Maryland, 1922-28. The numbers in this study are larger, ranging from about 200 to about 800 yearly, and all social classes are included. The standard deviations of the increments are given, but not the form of the frequency distributions. Probably this study is rather too old to be used as a standard nowadays; there has been considerable increase in the size of children at all ages during this century and data before about 1930 are to be avoided if possible: indeed the increase is still going on and the more recent the standardizing series the better. Lastly, Meredith and Meredith (1950) have published from the Iowa Child Welfare Research Station velocity standards for annual increments from 4 to 8 , the data being obtained from approximately 200 healthy children of north-west European ancestry and coming mostly from the professional and managerial class. The 10th, 30th, 70th and 90th percentiles are given for weight, stature, sitting height, arm length, leg length, shoulder width, hip width, and chest, upper arm and calf circumferences. The sexes are combined, there being no significant differences over this age range.

\section{Available Distance Standards}

Height and Weight. There are considerable numbers of distance standards available for height and weight, and a few which include additional measurements. These standards are obtained from cross-sectional studies, or from mixed longitudinal studies treated as though they were cross-sectional. The best height and weight standards available for English (and probably Scottish and Welsh) use at present are probably those of Gore and Palmer (1949) for age 0-5 years and Daley (1950) for age 6-17.

Gore and Palmer report on a cross-sectional sample made in 1947 of children in London infant welfare centres; 5,684 children were weighed but unfortunately only $\mathbf{9 2 1}$ had their length (or height) measured. Mean weights and standard deviations are given weekly to 4 months, monthly to 1 year and three-monthly thereafter. Boys and girls are reported separately, and each mean is based on between 80 and 200 children. The main criticism of this standard is that no frequency distribution of weights are given, and no percentiles, so that one must use the standard deviation method without actually knowing whether this is justified, and with weight the initial assumption must be that it is not. Gore and Palmer's height data are much scantier; means and standard deviations are given for six-monthly periods from 1 to 5 years, but some of the figures are based on less than $\mathbf{3 0}$ subjects. Also the technique of measurement is not given, and this is a rather crucial matter in measuring the length of small children.

There are at present two possible sources of standards for the 5-17 age groups. Daley (1950) has reported the height and weight measurements taken in 1949 on 21,000 London school children and gives the means, standard deviations, 10th, 50 th and 90th percentiles and the complete frequency distributions for each year, girls and boys separately. The 1st, 5th, 95th and 99th percentiles can thus be easily computed for the weight distributions, which are all skewed. Two objections can perhaps be laid against these figures; first that London children may not be a very good sample of all children throughout the country, and second that these children were weighed in their usual indoor clothes and by many different measurers and this always introduces inaccuracies and leads to standard deviations somewhat larger than they should really be. The weights reported include clothing (Daley, personal communication); to obtain nude weight probably about $7 \%$ should be subtracted. The first objection is probably not of much importance, since even if some small difference in mean weight and height exists between London and elsewhere this can be offset by using slightly altered percentile limits, as long as the scatter of the data in both places is similar.

Measurement Technique. The second objection is more serious. It must be emphasized quite clearly that all anthropometric measurements, including height and weight, need considerable care and effort in the taking, and unless done properly are not merely useless, but confusing. It is not sufficient to let an unskilled person measure height without detailed previous instruction, and it is not sufficient to weigh children now in one set of clothes and now in another. To take measurements properly demands very little more time and patience than to take them 
in a slovenly fashion, and unless the measurer is willing to expend this little extra energy it is better to leave measurement alone. Krogman's (1950) handbook on the measurement and interpretation of height and weight should be consulted in this connexion, also the remarks of Baldwin (1924). Briefly, stature should be measured with the subject standing as erect as possible, with heels, shoulders and buttocks touching an upright wall, the head poised so that the subject looks straight forward (external auditory meatus and lower border of orbit in the same horizontal plane), the occiput either touching or not touching the wall according to length of the head, and the heels together. A scale carefully ruled on manila paper should be stuck to the wall at an appropriate level, and a wooden D-shaped block should be brought down with the bottom face on the top of the subject's head and the rear face held against the wall. The subject is told to make himself as tall as possible without lifting his heels from the ground, and this is assisted by having him take a deep breath. Variation due to time of day is eliminated as much as possible by this latter procedure. Platform height scales are generally inaccurate and get more so with use and should not, therefore, be used; Krogman found errors of up to an inch on a selection of them. Height should preferably be taken with bare feet and in any case without shoes. It is useless to measure height with shoes on and apply a correction for heel height, for the simple reason that the lumbar curve is altered by the heel of the shoe being there. Weight should be taken on a beam scale and in the nude wherever possible. If not in the nude, standard clothing must be worn; either a smock as used in $\mathrm{x}$-ray departments or else drawers for boys and pants and a brassiere for older girls. The point is that the weight of the clothing must be the same for each child, and unless some standard arrangement is adopted it will not be the same (see Krogman's table of various weights of summer and winter clothes, etc.). Weights should be recorded as nude weights, the standard clothing weight being subtracted.

The technique for other anthropometric measurements need not be described here, as investigators usually seek the help of a standard text before plunging into these. But a word about the recording of age in standard tables may be said. Some tables have their label ' 6 years' refer to all children from $5 \frac{1}{2}$ to $6 \frac{1}{2}$ ('age at nearest birthday'), others to age 6 to 7; the user should make sure which he is dealing with in any given case. Also the width of the age interval makes a difference in the actual constructing of the standards. As the means and usually also the standard deviations of most anthropometric measurements rise with increasing age, the scatter amongst a group of children covering a six-month range is somewhat greater than the scatter of a group all of whom are exactly the same age. In the actual use of standards, however, it would probably be best to compare the child to be tested against the scatter of children of exactly that child's age. It is consequently desirable for standards to be made using the smallest age ranges that the magnitude of the data allows; three-monthly groupings are to be preferred to six-monthly or yearly. Alternatively one could correct for the gradually increasing standard deviation, but this does not seem ever to have been done in practice. The same considerations apply to the form of the distributions; if the height distribution of children all exactly 6 years old is Gaussian then that of children 6-61 years old will be slightly positively skewed and platykurtic; this difficulty reaches a climax at puberty.

Returning now to the main discussion, the second set of figures covering the 5-17 age range are those recently published by Sutcliffe and Canham (1950). These are based on a cross sectional sample of 17,000 children taken in 1947 and drawn in a more or less representative fashion from rural and urban areas over most of England. The 10th, 25th, 50th, 75th and 90th percentiles and the standard deviations are given for each year, for boys and girls separately. The curious feature of this data, however, is that the 10th and 90th percentiles for weight are symmetrical about the 50th percentile at all ages, which is contrary to practically all other published figures. It would seem that either these percentile points have been calculated on the assumption of a Gaussian distribution for weight, or else by some smoothing process. The 'indices' tabulated at the end of the book are, it appears, calculated on the assumption of a Gaussian distribution for weight, and so it seems wise to avoid using them at least until more stringent tests of the weight-distributions are published. It is noticeable also that though the medians for both height and weight agree fairly well between Sutcliffe and Canham's figures and the London ones, the standard deviations of the former are considerably lower. This is partly because the age group marked, for example, 6 years, refers only to the three-month range $5 \cdot 11 / 12,6 \cdot 0 / 12,6 \cdot 1 / 12$, and partly because the standard deviations were calculated not from the raw data but from the percentiles, assuming a Gaussian distribution (Sutcliffe, personal communication). It seems, as between the two sets of standards, that the London ones are at the moment preferable, though a reworking of Sutcliffe and Canham's excellent data is very desirable. 
Other Anthropometric Standards. Astonishing though it may appear, there are at present no British standards for any anthropometric characters other than height and weight; however, this deficiency will shortly be at least partly remedied, when the results of a Ministry of Health Survey made in 1945 under the direction of Dr. E. R. Bransby, are published: about 2,500 children, aged 5 to 18 , were measured, and 20 measurements were taken including height, sitting height, arm length, shoulder and hip widths, chest, waist, upper arm, knee, wrist and ankle circumferences, subcutaneous tissue folds and weight.

The main American standards with which the English should be compared, are those of Vickers and Stuart (1943), Simmons (1944), Gray and Ayres (1931), O'Brien, Girshick and Hunt (1941), Stuart and Meredith (1946) and Meredith (1946). Vickers and Stuart's data comes from middle and lower social class Boston children, and list means, standard deviations, range, 10th, 25th, 50th, 75th and 90th percentiles six-monthly from birth to 10 years for boys and girls for height, sitting height (or crown-rump at early ages), hip and chest width, head and chest circumference and weight. Simmons gives for Ohio upper social class boys and girls from 3 months up to 17 years means and standard deviations for 25 measurements including height, sitting height, shoulder, chest and hip width, chest circumference, arm length, and head length, breadth and circumference. Gray and Ayres give the mean and standard deviations for ages 1 to 19 of private school children of middle and upper social class for 15 measurements, including height, sitting height, shoulder, chest and hip width, chest circumference and weight: their monograph is still one of the prime sources of information in this field.

The U.S. Dept. of Agriculture survey reported by O'Brien, Girshick and Hunt comprises measurements on 147,000 children of all social classes, aged 4 to 17 , and is the biggest survey of its kind yet made. Means and standard deviations for each year are given for 35 measurements, but most of these, being intended for use in tailoring design, are not those thought to be best suited for medical purposes; however, height, hip width, leg length, chest, upper arm, thigh and calf circumference and weight are given.

Stuart and Meredith's are perhaps the best contemporary American standards, and the paper in which they are introduced is certainly the best statement of the problems involved in supplying and using standards since Shuttleworth's note of 1934. Dealing with the selection of measurements they strongly deprecate reliance on height and weight alone and point out that the time required to take three or four more anthropometric measurements is only a couple of extra minutes or so, and the value of the examination is thereby enhanced out of proportion to the extra time spent.

'It must be remembered that height is only one aspect of size, and that the stockiness or linearity of skeletal build is only one factor in determining body weight. Furthermore, body weight does not differentiate between the amount of protoplasmic tissue and the amount of fat or water stored in these tissues; nor does it distinguish between relatively inert tissues such as bone, and active protoplasmic tissues, principally muscle. It is important to recognize that heavy weight for age may be due in one case to stocky bones, in another to exceedingly well-developed muscles, in a third to large accumulations of subcutaneous fat and in a fourth to a relatively well balanced amount of all these. When a change occurs in weight for age it is important to know which of these tissues has changed sufficiently to bring this about.'

In an endeavour to estimate the various tissues by simple means, Stuart and Meredith recommend five measurements in addition to height and weight, namely hip width and chest circumference (these two with stature giving a guide to linearity or ectomorphy), calf circumference (to measure muscular development) and subcutaneous tissue thickness under the scapula and above the crest of the ilium. Directions for taking the measurements are given in full except for the subcutaneous tissue folds which should be measured with the calipers designed for the purpose by Franzen (1929, frontispiece) and used extensively by nutritionists and constitutional anthropologists (Meredith and Stuart, 1947). Stuart and Meredith (1946) give percentile standards for boys and girls from 5 to 18 years; these are illustrated in Fig. 3, which is reproduced from their paper. Their tables give $10 \mathrm{th}, 25 \mathrm{th}, 50 \mathrm{th}, 75 \mathrm{th}$ and 90th percentiles at half-yearly intervals: the data are from Iowa school children of the professional and managerial classes measured between 1930 and 1945. These measurements and standards, it may be remarked, were deliberately published for the guidance of school medical officers in assessing children's health and growth progress. For an example of their use see Stuart and Kuhlman (1942).

These American distance standards are quoted here partly as examples in standard construction and partly because of the lack of British data. It does not seem likely that they could be used for British children without some modification of procedure, since American children, apparently of all social classes, are bigger, on average, than British. The difference in mean height is about 3 to $6 \mathrm{~cm}$. from age 5 to 17 , with the gap widening a little at the beginning of puberty, probably due to American children beginning their adolescent spurt slightly 


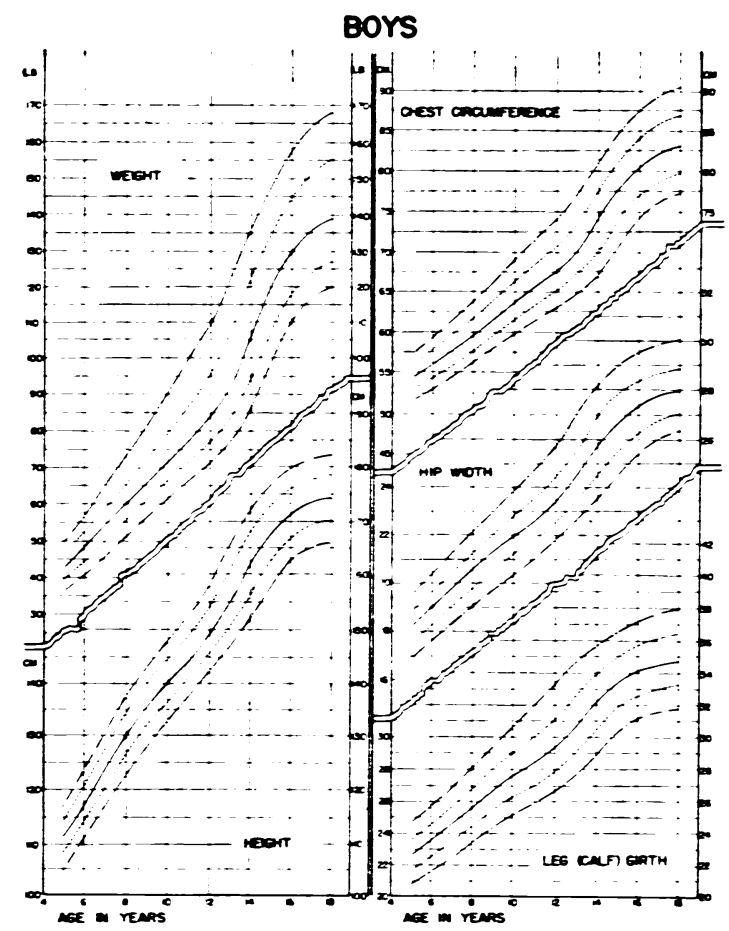

From " Use of Body Measurements in the School Health Program" by Stuart and Meredith (1946)

FIG. 3.-Stuart and Meredith's percentile distance standards: the five lines in each graph represent the 90th, 75th, 50th, 25th and 10th percentiles. Jowa children of professional and managerial class.

earlier. The mean weight difference is about $3 \mathrm{lb}$. at the beginning of this age range and rises to about $10 \mathrm{lb}$. by the end. The standard deviations for height are about the same, but the American spread in weight is greater than the British at all ages.

Those interested in standards for more recondite measurements will find lengths of arm and leg bones by radiograph from 6 months to 12 years in Maresh (1943) and Andersen and Green (1948), and fat muscle and bone breadths of the calf as determined radiologically in Stuart and Sobel (1946), Lombard (1950), Reynolds (1948), and Reynolds and Grote (1948). Regression standards and standards for maturity are discussed below.

\section{Use of Distance Standards for Assessing Velocity}

Before considering more complex standards of the weight-for-height-for-age type, we must pause to illuminate, if we can, one particularly murky corner of this field. There are a considerable number of authors who endeavour to use distance standards for judging velocity. Two alternative ways of doing this are illustrated in Fig. 4. In Fig. 4A the child's height measurement is simply plotted from year to year in the typical percentile distance chart. Starting out at about the 80th percentile the child falls back to the 10th percentile between 5 and 7 , and picks up again thereafter. The graph illustrates this well, but it takes us no further than simple illustration. The child in Fig. 4A never reaches our boundary of abnormality by reference to distance standards, even at age 7: common sense suggests that the increments from 5 to 6 or 6 to 7 are abnormally small, but Fig. 4A does not provide a test of this question; for this we need velocity standards with percentile charts of velocity from year to year.

The same is true of Fig. 4B, which is a rather more complicated way of dealing with the same data, but has some illustrative advantages. Here by developmental age is meant the age that the average child is when he reaches so many $\mathrm{cm}$. of height: the same concept is used in constructing intelligence quotients and in making the skeletal ratings discussed below. Thus the average child progresses exactly up the diagonal line in Fig. 4B, with chronological and developmental ages always equal. The particular child we are considering, however, is in advance of average at age 2 , then drops slightly behind in height, until at age 7 he is only the height of the average child of 6 . This method has the disadvantage that usually neither distance nor velocity percentiles are shown; and having a 'height developmental ${ }^{\circ}$ age a year less than chronological at age 4 implies considerably different conclusions from having the same difference at age 12 , as may be seen by comparing percentile positions in 4A to developmental age advancement in $4 B$. Distance percentiles could be put in such a chart to remove this objection, but the trouble with velocity percentiles would remain. Admittedly - developmental age ${ }^{-}$in several measurements can be plotted at once on this type of graph-we can put in weight developmental age, hip width developmental age and also skeletal and mental age-but the interpretation remains highly subjective. The best example of the use of this graph will be found in Wilkins" recent textbook (1950).

The method of Fig. 4A certainly has a great deal to commend it. Particularly when the record extends over several years the visual comparison of the subject's curve to the standard ones may be most illuminating. Also the situation may arise when a child suffers a succession of somewhat decreased velocities, none overstepping the limits of normality, but cumulatively producing an abnormally small child, as revealed, eventually, by the distance chart. It would seem perhaps best to use two percentile charts side by side in assessing growth in single measurements, one chart of distance and the other of velocity. Such a combined chart is given in 
Fig. 5A, B, C, D. The data are those of the Brush Foundation from Simmons (1944) and Simmons and Todd (1938); standard deviations have been put in instead of percentiles because the data are only given in this form; percentiles would probably be preferable.

The two standards together enable one to assess both size and velocity and should therefore be more critical than any single-measurement standards using the same measurements now in use: only experience will show whether the expectation is borne out in

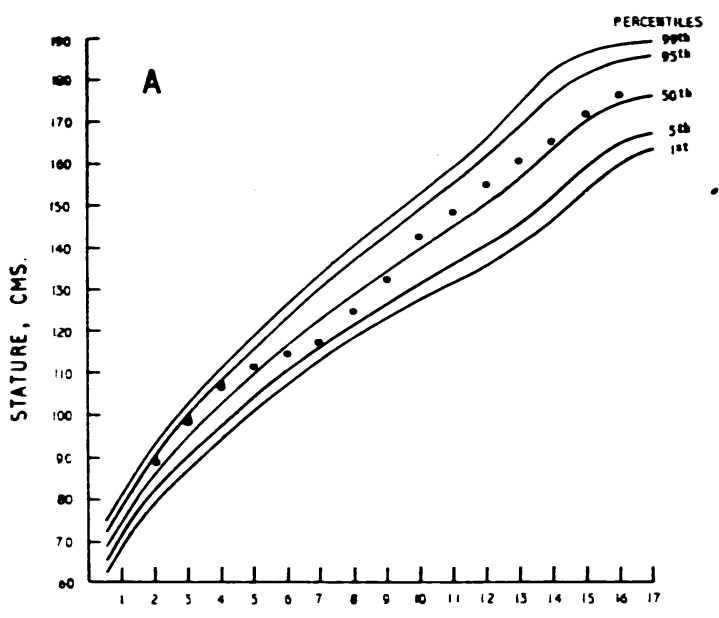

CHRONOLOGICAL AGE, YEARS

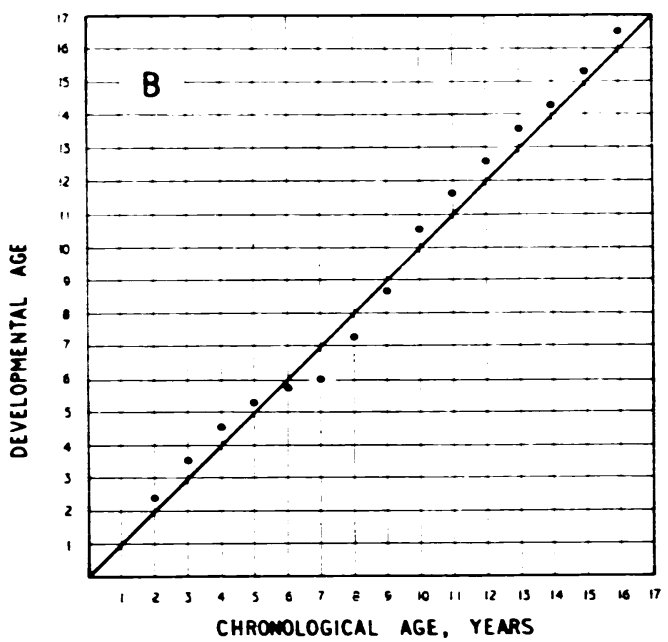

FIG. 4.-Growth of a hypothetical child with retardation from age 5 to 7 . 4A. Plotted on the normal percentile type of distance standard. 4B. Plotted as chronological age versus developmental age. Note that neither method gives a test for abnormality of velocity. practice. For more precise standards still one would have to use deviations from growth curves over several years; it might be sometimes practically important to do so, particularly in orthodontic work (see Count, 1942). A system of standards using distance and velocity data for single measurements and in addition, the relation of one measurement to another, is given below.

\section{Multiple Measurement Distance Standards}

So far we have discussed only the use of single measurements for detecting abnormality. We have seen that a battery of such measurements, about seven in all, is the procedure recommended on biological grounds, but we have not discussed how the results of these seven measurements should be related together to give us an overall diagnosis. But if a child's scores on the seven measurements are six 75th percentiles and one 97th percentile, what are we to say? He is abnormal on one measurement, according to our single-measurement standards, but normal on six others. Again, if we had two children of the same age, one at the 95th percentile for height, weight and hip width and the other at the 95th percentile for height and hip width but the 5th percentile for weight, we would come to radically different opinions about the two; one is quite simply a large child, the other a child with a large skeleton and a probably abnormally small amount of muscle or fat or both. Clearly the relationships between two or more measurements give us added information about the child, information that we have so far neglected.

The complexity introduced into the situation as soon as we take two measurements instead of one seems not to be widely realized; with the second measurement we are well into the statistical jungle, populated only by a few semi-domesticated mathematicians and an occasional exotic psychologist. The trouble comes about this way: if we agree to call abnormal all children falling below the fifth percentile in height or in weight, then the number of normals called abnormal will no longer be five in 100, but more. Out of every 100 normals we shall ' reject' (used from hereon to signify 'call abnormal ') five on the basis of height and five on the basis of weight. If height and weight bore no relation to each other our total rejection would be $5-5=10$, but since they are related some of our height-rejected children will be the same individuals as the weight-rejected, and the total rejected will be somewhere between five and 10 . If we use height and weight in this way, in other words, we have altered our definition of ' abnormal ', for we defined it in the single-measurement case so as to reject just $5^{\circ}$ o of normals (or other fixed percentage). 

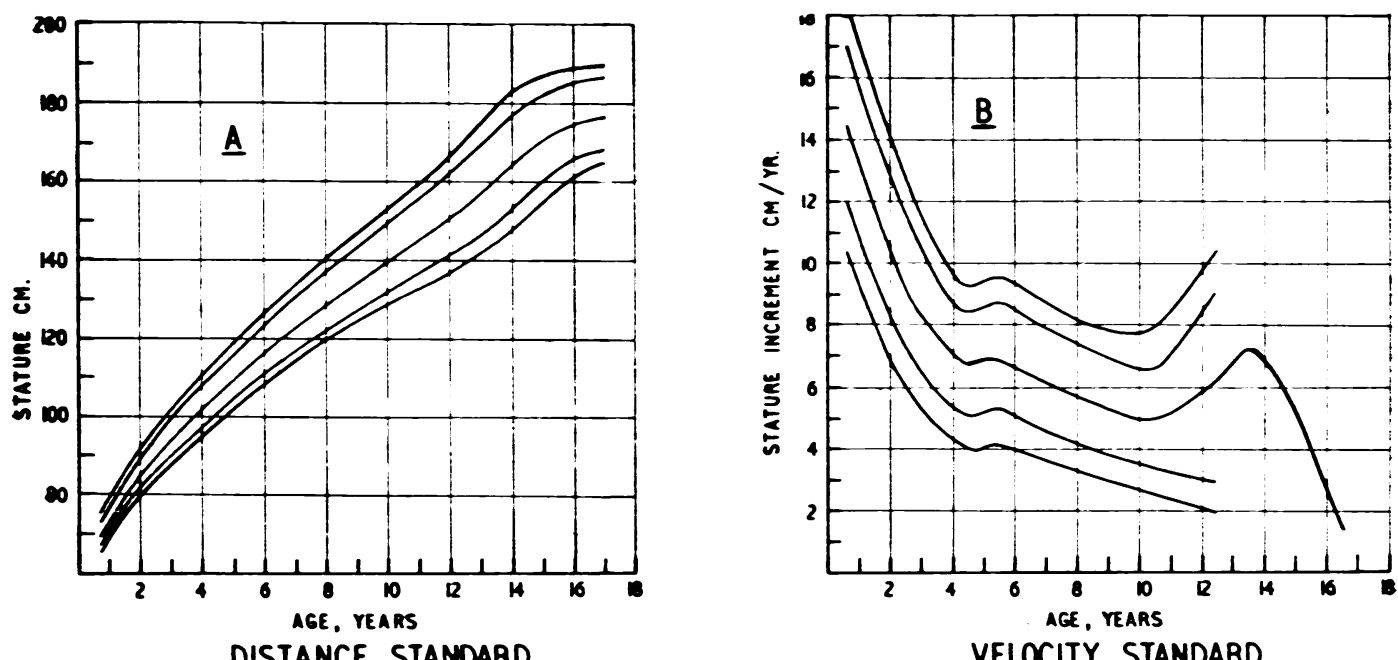

DISTANCE STANDARD
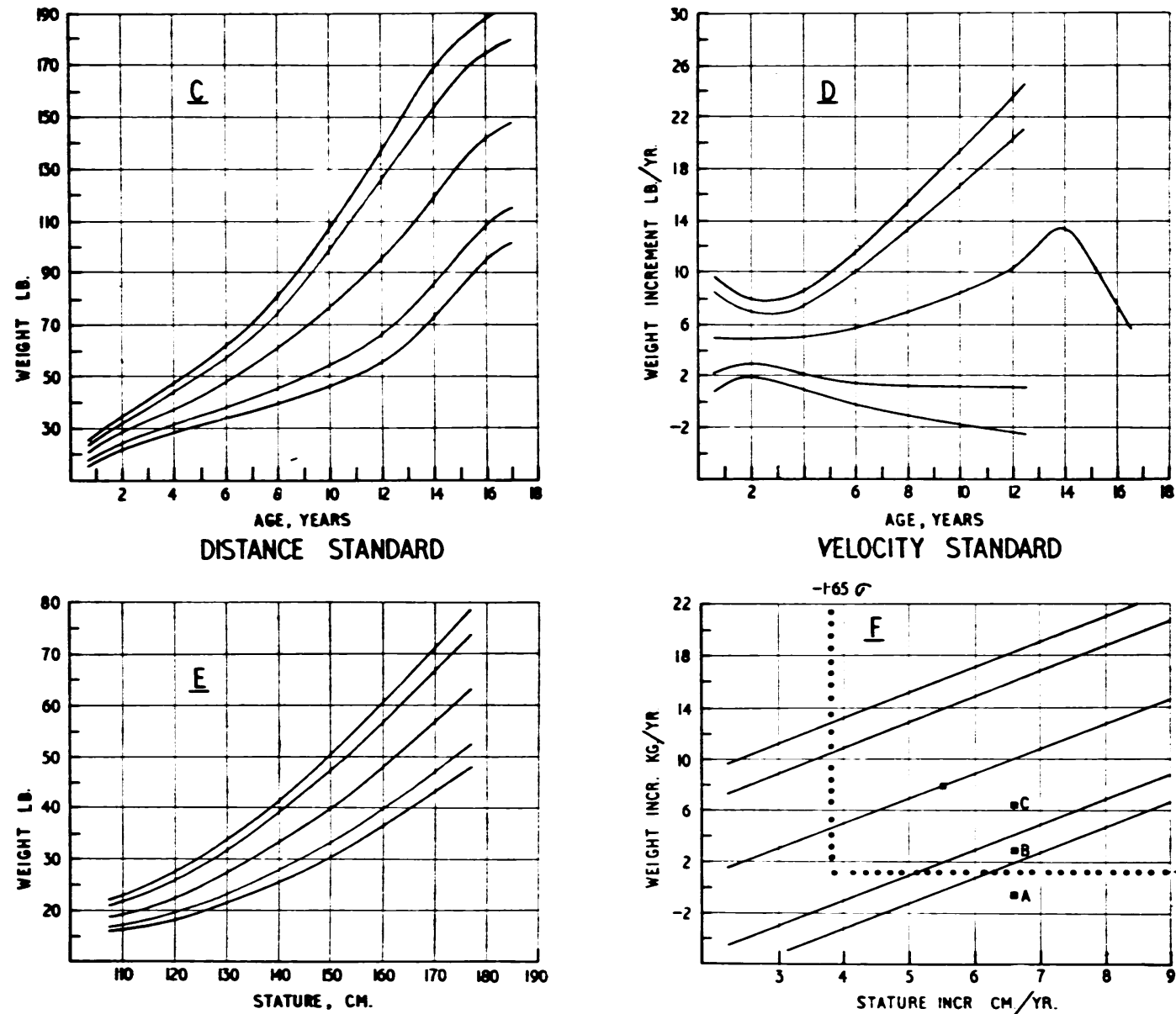

DISTANCE STANDARD

REGRESSION IRRESPECTIVE OF AGE

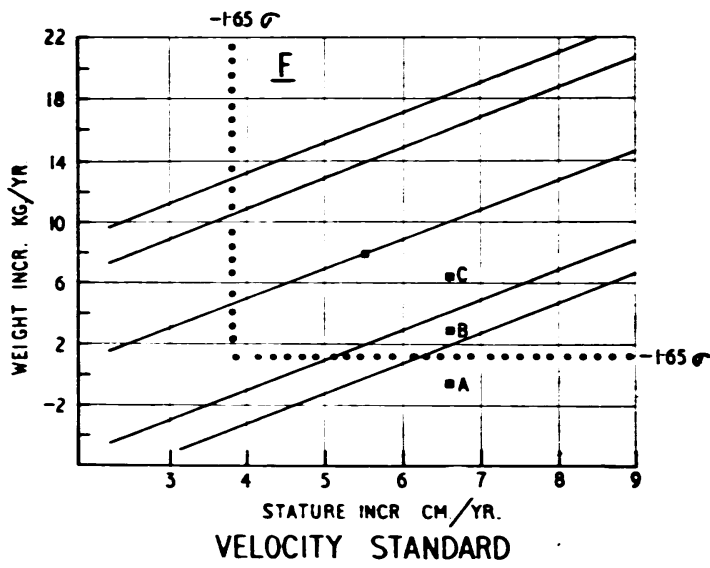

REgRESSION VITHIM AGE, 9-10

Fig. 5.-To illustrate suggested form for standards using two measurements only: a combination of distance velocity and regression data. Data in A, B, C, D and F are from Simmons (1944) and Simmons and Todd (1938) on Brush Foundation boys; for E from Daley (1950) for London County Council boys aged 5 to 16. The $\pm 1.65 \sigma$ and $\pm 2.3 \sigma$ lines correspond to the 5th, 95th and 1st, 99th percentiles in A and B; in C, D and E probably about the 2nd, 93rd and 1/10th, 97th percentiles: in F uncertain. 
It will be seen that Stuart and Meredith's standards, amongst others, are subject to this uncertainty in interpretation.

Construction of Standards. We can meet this situation only by arranging our consideration of the two or more measurements so that in the end only $5^{\circ}$ o of normals are rejected by our total procedure, whatever it is. We have to combine height and weight somehow. This is very simple to do; we can use a thousand combinations: height/weight, height $/{ }^{2}$ w weight, height $/{ }^{3}$ ' weight, height $/$ log. weight, log. height $-\log$. weight, height $x$, weight $\beta$, anything. For each we can find a figure such that $5^{\circ}{ }_{0}$ of normals are rejected. But the various combinations will differ in the number of abnormals picked out for that $5^{\circ}{ }_{o}$ normal rejection; some will be powerful enough to pick out most of the abnormals, others will detect very few and hence have little practical value. It is in choosing our combination, that is in deciding the relative stress to be laid on height, weight, subcutaneous fat and so on in diagnosing abnormality, that we find ourselves statistically pathless, except in one set of circumstances, which we had better describe before going further.

When the characteristics of the abnormal, unhealthy population are known, besides those of the normal population, then we are in no doubt as to the correct procedure. In this case, we can calculate a line so that it separates, on the basis of two or more measurements, the abnormals from the normals with $5^{\circ}$ o (or any other chosen figure) normals rejected and the minimum percentage of abnormals undetected. Those above the line are normal, those below abnormal, only $5^{\circ}$ of normals are misclassified, and our objective is achieved. The line is called a discriminant function. If the scatter of normal and abnormal populations is the same for, for example, height and weight, and the correlation of height and weight is the same in both populations, the line is a straight one, but if the scatters or correlations are different, as is much more likely in practice, the line is curved, an equation of the second degree (Smith, 1947). Not having any data available on groups of known well-nourished and ill-nourished children to take as an example, we must be content with an illustration from data previously reported (Tanner, 1951b). This is a situation in which we are trying, a trifle foolishly, to discriminate men from women (normals from abnormals) by shoulder and hip widths: if we have two measurements, biacromial and bi-iliac, the line which best discriminates is the one marked 'overall' in Fig. 6A; its equation is

$$
3 \text { biacromial diam. }- \text { bi-iliac diam. }-82=0
$$

and it misclassifies the minimum number of men plus women. Parallel to this line we can draw others, misclassifying $5^{\circ}$ of the men only or $1^{\circ} \%$ of the men, as shown. The $5^{\circ}$ o line, the one we particularly want, is approximately

$$
3 \text { biacromial diam. }- \text { bi-iliac diam. }-81=0
$$

In short, we have calculated a combination of two measurements which, if more than 81 , indicates normality, and if less than 81 , abnormality. The combination we have calculated is the best combination; that is, it detects the largest possible number of abnormals for $5^{\circ}$ o normals rejected. One can try to distinguish men from women by the use of the ratio hip width shoulder width, for example, but for $5^{\circ}{ }_{0}$ of men misclassified, a much greater number of women remain undetected among the men than by using the discriminant function line. The use of the discriminant can be extended to any number of measurements; in the example given the equation

$$
\begin{gathered}
2 \text { biacromial diam. }-0 \cdot 53 \text { subischial (leg) length } \\
-1 \cdot 25 \text { bi-iliac diam. }-81=0
\end{gathered}
$$

discriminates better than the two-measurement equation above.

In practice there are great difficulties in setting.up standards this way, desirable though they would be. To use them we must know the characteristics of both populations, and this we seldom do. If we wanted, therefore, to use these standards as a screen for malnutrition from the usual variety of causes -economic hardship, maternal inefficiency, family disorganization, psychological disorder of child or parents-we would have to have located children whom we knew were quite definitely malnourished, and this is not easy. Stuart (1948) has well said that the therapeutic test of giving the child a known adequate food intake in a holiday surrounding with known psychological stabilization is the only sure way of telling whether a child has suffered retardation of growth progress through malnutrition. If the screen is to include lack - or excess - of growth progress through other factors such as the various endocrine disorders, the abnormal population becomes yet more difficult to locate and handle; its distribution is likely to be skewed and perhaps multimodal.*

When we do not know the characteristics of the abnormal population, or when they are simply too complicated to handle, we are forced to choose some combination of the measurements, locate the fifth percentile level for our normal limit, and hope that we are picking out as many abnormals with it as possible. There are no statistical grounds to guide us, and if we choose one combination rather

\footnotetext{
- That is, having several peaks instead of one.
} 
than another, it is on an empirical or intuitive basis that we do so. The combination can be chosen in a number of ways, three of which are illustrated in Fig. 6B, C and D.

In Fig. 6B we follow the straightforward idea of using $-1.65 \sigma$ for biacromial and $-1.65 \sigma$ for bi-iliac as lower limits of normality for the men, but since these lines would exclude from the unhatched area not $5^{\circ}$ o of men but more, the limits are set at $-2 \cdot 0 \sigma$, which is the multiple of each standard deviation which does lead, empirically in this sample, to $5^{\circ}{ }_{0}$ misclassified. Here we are giving equal importance to both measurements in the diagnosis. Should we do the same if we had height and weight and were trying to discover if a child were malnourished ? Most would say not; more importance would be given to weight, but how much more? Twice as much so that the lower weight limit is something like $1 \cdot 8 \sigma$ and the lower height limit $2 \cdot 2 \sigma$ ? Or three times as much ?

Several alternative ideas, some used in practice, suggest themselves. Fig. $6 C$ illustrates one. Here the regression* of one measurement on another is taken for males and the -1.65 s limit for the biacromial-predicted-from-bi-iliac diameter used as the separating line (marked $-1.65 \sigma_{\text {est }}$ in figure). Correnti (1948-49) has used an elliptical area with the regression line as the major axis, rather than the $-1.65 \sigma$ est line parallel to the regression line; his arrangement has some advantages. Or some ratio, biacromial/bi-iliac diameter, weight/height,

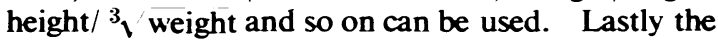
methods of Fig. 6B and C can be combined as in Fig. 6D, which gives some importance to both absolute size of measurement and the relation of one measurement to another.

Regression standards have been widely used, and must be discussed at some length. They will probably be familiar to the reader, though perhaps not under this name. The weight-for-height-for-age tables are the commonest example, the best known being those due to Baldwin and Wood (1923 ; Baldwin, 1924, 1925) and to Faber (1929). In this type of standard the expected weight is given corresponding to the various possible heights, and this is done for each year of age separately. Suppose we have a boy aged 10 whose height is $140 \mathrm{~cm}$. and weight $72 \cdot 5 \mathrm{lb}$. Finding 10 years in the table, we

* If we have two measurements $x$ and $y$ we can relate them by means of a line which predicts the most likely value $Y$ for any given value of $X$. This line

$$
\boldsymbol{Y}=\boldsymbol{a}-\boldsymbol{b} \boldsymbol{X}
$$

where $a$ and $b$ are constants, is called a regression line. Unless the measurements are perfectly correlated one with another the prediction of $Y$ from a value of $X$ is subject to a certain amount of error: most of the points do not actually lie quite on the line, but round about it. The amount of this error in prediction is measured by the statistic $\sigma$ est, the standard error of estimate. Its interpretation is that of all the values actually obtained for $Y$ at a given value of $X$ about $95 \%$ lie within the range $=2 \sigma$ est from the predicted value of $Y$. look up the expected weight of 10-year-old boys of $140 \mathrm{~cm}$. height and find it to be $78 \cdot 5 \mathrm{lb}$. The boy is $6 \mathrm{lb}$. below the average weight for his height at this age. If the tables have been properly constructed, we should also find the percentile spread about the expected weight figure, or the standard deviation around the expected figure (the standard error of estimate, in the usual terminology of the regression equation). The Baldwin-Wood tables give only the mean expected figure, however, and Faber gives only the 10th and 90th percentiles. Let us suppose the standard deviation around the expected value is $9 \mathrm{lb}$; the boy is then $6 / 9=0.67$ standard deviations below the expected mean, and if we pretend for the moment that weight has a more or less Gaussian distribution for given height, then this corresponds to about the 25th percentile, which is not very far down the total list of boys. A regression standard (for increments this time) is shown graphically in Fig. 5F, the central line being the expected weight increment for height increment and the parallel lines the $=1 \cdot 65 \sigma$ and $\doteq 2 \cdot 3 \sigma$ limits for the estimate. (The data are from Simmons and Todd (1938) and a linear regression of weight increment on height increment and also homoscedasticity* has been assumed, perhaps unjustifiably, for illustrative purposes and because data on the point are lacking.) In Fig. 5F the lower $1.65 \sigma$ limits for weight increment and height increment have also been indicated. If we were judging by the regression standard, the child designated by $B$ in the figure would be called abnormal; if we were judging by weight increment only, $B$ would be normal, being just above the $1 \cdot 65 \sigma$ level. Child $C$ would be normal in either case, and child $A$ abnormal, but if we used the technique shown in Fig. 6B, giving equal importance to both variables and rejecting $5^{\circ}{ }_{0}$ only, then even $A$ would probably be judged normal, as the lower limit for weight would be somewhere about $1 \cdot 8$ to $2 \cdot 0 \sigma$.

This is merely repeating what is already shown in Fig. 6; in each drawing A, B, C, D, $5^{\circ}{ }_{0}$ of normals are rejected, but not the same individuals in each. In Fig. 6 we have the discriminant function line which we know is the best one and we can compare the other techniques with it. The regression method (6C) in this example comes out better than any set of horizontal and vertical boundaries drawn after the manner of $6 \mathrm{~B}$; it detects only two fewer abnormals than the discriminant. Whether regression standards are preferable to standards of the 6B type in all or even most circumstances in child growth is not known at present. The efficiency of any regression depends first on the correlation

* Equality of variability in $Y$ (weight) for each broad division of $X$ (height). 

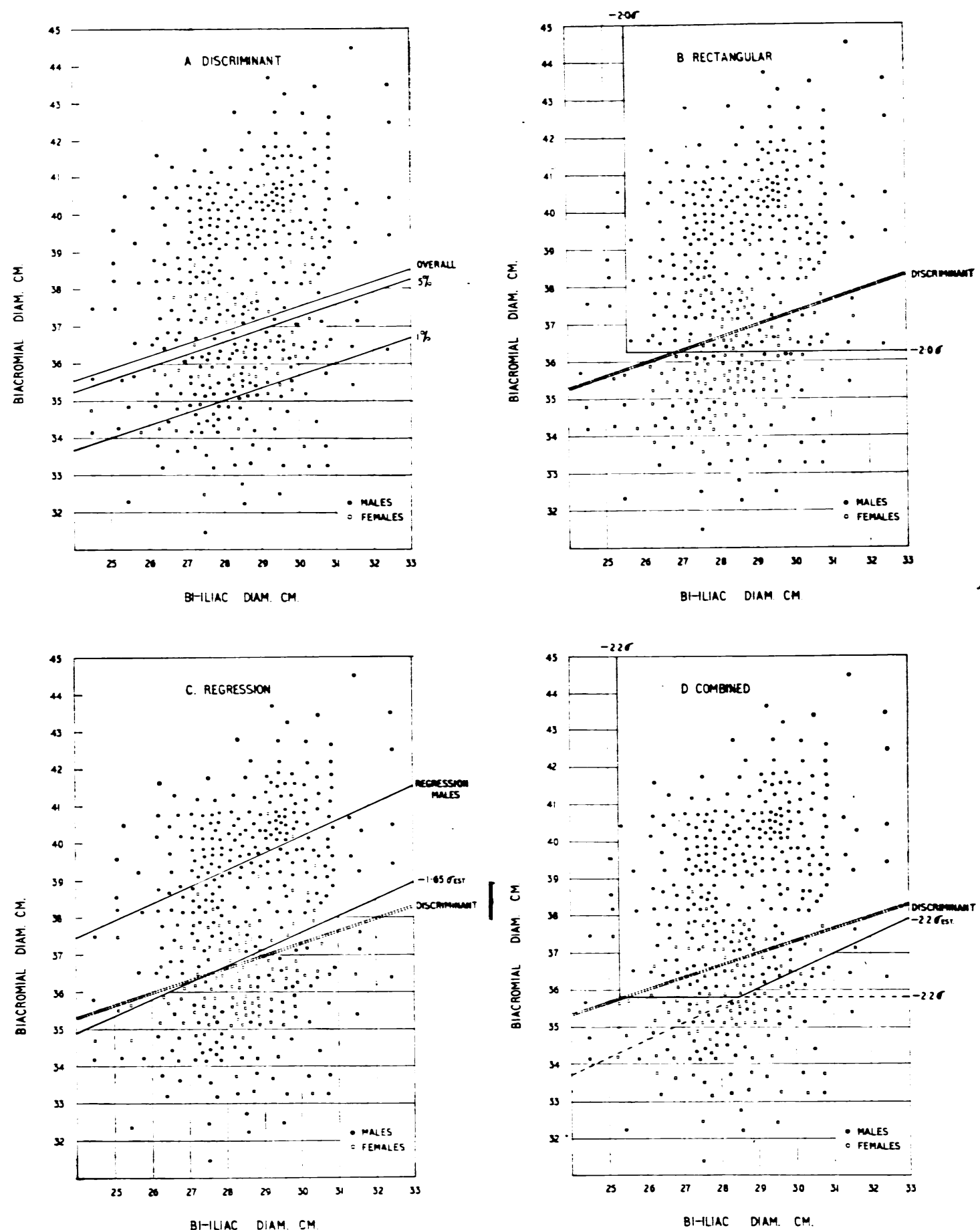

FIG. 6.-Four possible sorts of multiple measurement standards. In each case the hatched area represents the area of abnormality, defined so that $5 \%$ of normals are called abnormal. Males are taken as normals, females as abnormals. Fig. 6A. Discriminant lines, giving best separation of normals and abnormals. Fig. 6B. Equal importance given to both measurements singly; 25 fewer abnormals detected than by discriminant. Fig. 6C, regression standard; 2 fewer abnormals detected. Fig. 6D, combination of $B$ and C; 31 fewer abnormals detected. 
between the two measurements (since if there is no correlation the relating together of the two is simply an irrelevance), and second on the disease process, whatever it is, altering one measurement and not the other. If the disease causes both measurements to alter proportionately, then their relationship stays the same, and, if the child's point falls on the regression line to start with it merely moves up or down the regression line (see Fig. 6C) and not away from it. In such circumstances the technique of Fig. 6B would be better, for by this method the proportionate increase or decrease will be detected, the child moving from, say, a position of $-1.0 \sigma$ in both measurements to the abnormal position of $-2 \cdot 3 \sigma$ in both.

The construction of regression standards is a simple matter. If two anthropometric measurements are adequately related by a straight line, and if the $y$-axis measurement is distributed in a Gaussian form for each broad division of the $\mathrm{x}$-axis measure, then the expected value $Y^{\prime}$ of any measurement for the value $\mathrm{X}$ of another measurement is

$$
\mathbf{Y}^{\prime}=\mathbf{a}+\mathbf{b X}
$$

where $a$ and $b$ are constants obtained for the standardizing data by simple statistical procedures; $b$ is known as the regression coefficient. The standard deviation around this expected value $Y^{\prime}$, $\sigma_{\text {est, }}$ is also simply estimated, and if $I$ is the correlation between the whole series of $\mathrm{X}$ and $\mathrm{Y}$ measurements at this age $\sigma_{\text {est }}=\sigma_{\mathrm{y}} \sqrt{1-\mathrm{r}^{2}}$ where $\sigma_{\boldsymbol{Y}}$ is the standard deviation of all values of $Y$. (In this section and above $I$ have assumed large samples and avoided discussing problems of estimation, not because they are unimportant, but because they would complicate the exposition intolerably.) The principle can be extended to more than two measurements; $Y^{\prime}$ can be predicted from $X, Z, A$ and $B$ by, for example,

$$
\mathbf{Y}^{\prime}=\mathbf{a}+\mathbf{b X}+\mathbf{c Z}+\mathbf{d A}+\mathbf{e B}
$$

with a $\sigma$ est of $\sigma_{y} \sqrt{1-R^{2}}$ where $R$ is the multiple correlation of $\mathrm{Y}$ with $\mathrm{X}, \mathrm{Z}, \mathrm{A}$ and $\mathrm{B}$. If the relationship of one measurement to another is not adequately represented by a straight line, but requires a curved one, the same principles still hold. The situation is then as illustrated in Fig. 5E; curved percentile lines run either side of the curved line of expected weight.

In using the regression standard one may calculate from the standard the expected weight, say, for the measured height, and then compare the difference between this and the actual weight with the figure for $\sigma_{\text {est }}$, as in the example above. For this procedure to be valid it must be emphasized that two conditions must be met. The distribution of weights for any given broad division of height must be Gaussian, and the standard deviation of the weights must be the same for all height divisions (i.e. normality and homoscedasticity of weight arrays). If the former condition is not met then percentiles must be used, and if the latter is not met, then different standard deviations or percentiles must be used for each division of height, a laborious business. These considerations apply whether the regression line is straight or curved, rectilinearity being a separate issue. Since in general one cannot find transformations which simultaneously reduce the relation to one of rectilinearity, homoscedasticity and normality of array distributions, it is necessary to decide which reduction is the most important. This would seem to be the production of a Gaussian distribution in the arrays, with homoscedasticity of arrays as the next desideratum. Rectilinearity comes last. Some standards have been proposed-for example, the Wetzel grid discussed below-in which rectilinearity has been achieved over considerable ranges, but at the expense of non-Gaussian array distributions. Though such standards can be used with percentiles instead of standard deviations, their construction does not seem a very appropriate one.

Regression standards in current use are divisible into two classes; those which operate over a restricted age group, which we will call 'within-age regression standards ${ }^{\circ}$, and those which operate quite without reference to age at all, which we will call 'irrespective-of-age regression standards. ${ }^{\circ}$ Fig. $5 \mathrm{~F}$ is an example of the former, and Fig. 5E of the latter. In Fig. 5F the standard holds only for the age range 9-10 years, and is one of a set of similar regressions, one for each year of age. The BaldwinWood and Faber tables are regressions of this sort. But instead of this we can ignore age and simply use a weight-for-height regression covering the whole period of growth, as in Fig. 5E.

It is essential to have clear the difference between these alternatives. In the first case, we test the child $\mathbf{M}$ on the basis of weight-for-height at his age, and place him in relation to the expected mean and standard deviation for boys of his chronological age. In the second, we test $M$ on the basis of weight-forheight at his height and place him in relation to the expected mean and standard deviation for boys of his height. Thus, if we have a boy aged 10 who is advanced for his age both in height and weight, the first method will predict his expected weight by a regression coefficient appropriate to 10-year-olds, and compare his deviation from the expected value with the $\sigma$ est for 10-year-olds. However, the boy may perhaps be better regarded as nearer the average 11-year-old state, since he is about an 11-year size, and the regression coefficient for 
11-year-olds is larger than that for 10 . The expected value would therefore be somewhat different, and so the deviation would be different. Also the $\sigma$ est would probably be larger at 11 than at 10 , and the result of the test pretending the boy was 11 would be different from that made keeping him at 10 . Only in one circumstance will this not be true; if the expected weights for both year groups are the same, and the deviations from expected weights in each of the groups are proportional to the standard deviations of the groups, then the test result will be the same whichever group the boy is tested in. (This is now on the assumption that we are using a transformation of weight which brings it to a Gaussian distribution.) For the expected weights to be the same the regressions must be the same for both age groups and the coefficient must be equal to the average weight gain from 10 to 11 divided by the average height gain: for the second condition above to be satisfied we must have the same height-weight correlation at both 10 and 11 . When these conditions are met for all age groups then there is no difference between the two alternative regression methods. If the condition of equal correlations at all ages is met, as it is fairly closely at least up to the last two or three years of growth (Tanner, 1951a), then the conditions reduce to mean yearly gain in weight/mean yearly gain in height being constant, and equal to standard deviation of weight/standard deviation of height, the latter ratio being the same for all age groups. These conditions are not met by weight and height in their usual measurement scales, but they are met by using standard scores as described below.

Considerable numbers of distance regression standards have been suggested, most of them of the within-age variety, which have the advantage of being nearer rectilinearity for most combinations of measurements than irrespective-of-age regressions. Most of these standards aim at predicting body weight from various skeletal and/or muscular measurements. Pryor's $(1936,1941)$ tables predicting weight from height and hip width are of the best known and are given in Holt and McIntosh's textbook (1940). The idea is that the two skeletal measurements give a fair idea of skeletal size and build, and then weight ought to follow accordingly, but weight in fat and weight in muscle are not, of course, distinguished. The most thorough studies of weight prediction by various combinations of measurements are those of Franzen (1929), McCloy (1936, 1938) and Dearborn and Rothney (1938). The first of these accounts in particular deserves to be better known than it is at present; it covers with clarity and distinction a great deal of the ground surveyed in this paper. Franzen discussed the prediction of weight from four skeletal measurements, but suggested that for nutritional purposes weight prediction standards are not as good as prediction of upper arm girth, calf girth and subcutaneous tissue thickness over the biceps. The former two are predicted from height, chest breadth, chest depth and hip width, and subcutaneous tissue is predicted from height, chest breadth, chest depth and shoulder width. Franzen's regression standards were tested in the field by Mitchell (1932) who used them successfully to pick out malnutrition in Porto Rican children and relate this to such factors as family income and overcrowding. Mitchell's paper also seems to be less well known than it deserves. Massler and Suher (1951) have recommended a ratio type of standard, weight being predicted by (calf circumference) ${ }^{2}$ stature divided by a constant, which is independent of age over the range 5 to 17 . No percentile limits or tests of distribution are given.

The Wetzel Grid. A consideration of the Wetzel grid $(1941,1943,1944)$ standard falls due at this juncture. Armed with the discussion above, courage, a magnifying glass and steady nerves, the reader will be able to make out that the grid. reproduced in Fig. 7, is in essentials simply a weight-for-height regression distance standard, presented with a recommendation to use it as a velocity one. The regression standard is neatly combined with a distance-for-age standard, and is of the irrespective-of-age type, with a logarithmic transformation of both weight and height used to get the regression from the curve of Fig. 5E above to a straight line, at least from age 6 onwards. Look first at the left hand portion of Fig. 7: the graph is one of $\log$ weight vertically against $\log$ height horizontally. Consider a child $\mathbf{M}$ of height $130 \mathrm{~cm}$. and weight $26 \mathrm{~kg}$.; locate the point, ringed in the figure, which corresponds to these figures. Look at the 'physique channel' lines running north-eastward, and it will be seen that $M$ lies in channel B1, near the B1-B2 boundary. Since the middle channel corresponds to the average child, this $\mathbf{B} 1$ position tells us that $M$ weighs a bit less than the average child of his height. If we go up to the $130 \mathrm{~cm}$. vertical line till we get to the middle of the centre channel $M$ we find the weight of the average child of this height is actually $28 \mathrm{~kg}$. This information, then, is the same as that given by a weight-for-height distance regression except that it is less precise, since no standard deviation $\sigma$ est about the mean expected weight is given. We cannot judge how far down amongst his height group a weight of $2 \mathrm{~kg}$. below average brings $M$. That it brings him to the B1-B2 border does not of itself tell us what we really want to know, which is his 
percentile position. The channels may be actually misleading in this regard to the unwary; from their graphic presentation as of equal width one might readily assume that the distribution of $\log$ weight for log height was Gaussian and homoscedastic about the mean of channel $M$. Whether or not this is so still cannot be discovered from the published studies; Hopkins (1947) gives a graph of log weight against $\log$ height for girls aged $6-12$, and in this it looks as if log weight is still skewed, particularly for the larger girls. For a given size (that is auxodrome 100 , see below) the distribution of log weight is certainly heavily skewed with an excess of cases in the B channels below the mean (Wetzel, 1941), so that being in channel B2 at what almost amounts to a given log height implies a percentile position considerably nearer the 50th than does being in A2. Also one must remember that though these lines are called 'physique channels', M's position in them really tells us very little indeed about his physique in the true sense. It takes a great deal more than simple weight for height to characterize a human body, in which connexion the remarks of Stuart and Meredith quoted above are pertinent.

Now consider the line passing in an east-south-east direction through $\mathbf{M}$ 's position on the grid. It is called 'isodevelopmental level ${ }^{\circ}$ and marked 70. Follow it down to the right hand portion of the chart and consider this portion. It is seen to be simply a percentile chart of growth with age, the same as those in Figs. 3 and $4 A$ and $4 C$, except that the vertical scale is neither height nor weight, but a composite of the two. If, for example, $M$ was $130 \mathrm{~cm}$. tall but weighed $29 \mathrm{~kg}$. instead of $26 \mathrm{~kg}$., his level on the right hand chart would be 80 ; if his weight were $26 \mathrm{~kg}$. but his height $120 \mathrm{~cm}$. instead of $130 \mathrm{~cm}$., his level would be about 67 . A change in weight of $3 \mathrm{~kg}$. is not a great deal, yet it produces a far greater effect on isodevelopmental level than a change of $10 \mathrm{~cm}$. of height, which is quite a lot. The composite measurement is of the same nature as surface area, also obtained from a combination of weight and height, but it gives much greater emphasis to weight as opposed to height than does the DuBois expression for surface area. The idea of using a composite of the two measurements to measure size for age is undoubtedly a good one, but this particular composite is probably not the best available. Presumably what is theoretically required is something approximating the general size factor for body build, and at least in adults, as I have pointed out elsewhere (Tanner, 1949c), this is very closely approximated by the DuBois surface area. Returning now to $\mathbf{M}$, we disclose his actual age as 10 years, say. Follow the 70 line to the right till it meets the vertical 10 year line at the ringed point. A percentile line goes.through this point: $\mathrm{M}$ lies on the '82nd percentile ' of size for age. This is approximately the same information as is obtained by reference to Meredith and Stuart's curves of Fig. 3, or those of Figs. 4A, 5A and C; it is not quite so full, however, in that it gives only a somewhat questionable ' size ${ }^{*}$ rating instead of separate height and weight ratings. Note also that Wetzel gives his percentiles in the opposite sense to those in Figs. 3 and 5, marking the children from the bottom up, so to speak. In addition, the middle of the percentile lines given in Wetzel's chart is not, as one might expect, the 50th percentile, but the 67 th, or in the more usual terminology, the 33rd. A ' size developmental age ${ }^{*}$ is given by reference either to this 67 th percentile or, by some later authors, to a 50th percentile precisely as for the height age graphed in Fig. 4B; the size developmental age is the age at which the 67th (or 50th) percentile crosses the horizontal line reached by the child, in the case of $M 8 \frac{3}{4}$ years for the 67th percentile, about $8 \frac{1}{2}$ years for the 50 th.

Wetzel now recommends this procedure to be followed for $M$ every year, when a series of points will be produced on both left and right hand portions of the chart. These, plotted in solid dots, are for the same hypothetical child who gave the points in Fig. 4A and $\mathrm{B}$. The dots on the right hand portion are precisely similar to those in Fig. 4A except that Wetzel's measure of size is plotted instead of height. From the point of view of interpretation the situation is just the same as in Fig. 4A; graphically the drop in velocity between 5 and 7 years is shown quite well, but no tests of whether the drop is abnormally large or not can be made. We are again using a distance standard for judging velocity. The dots on the left hand chart require a little more analysis. Wetzel assumes, it seems from $a$ priori consideration, that from about 6 years onwards a healthy individual travels a straight course up one of the channels, in other words, maintains a constant ratio of $\log$ height $: \log$ weight. This is certainly true of the mean values of such data as of the Brush Foundation (Simmons, 1944) and is very nearly true for the mean values of the London County Council data (Daly, 1950). If a child slips out of his channel in a southerly direction, as does the one illustrated in Fig. 7, then he is said to be gaining too little weight for his gain in height, and if he deviates to the north he is said to be gaining too much weight for his height. Again, the method is very aptly illustrative, and by using logarithms Wetzel has obtained a straight line regression for weight on height over a fairly large age range, which is certainly desirable, though not at the expense of producing 


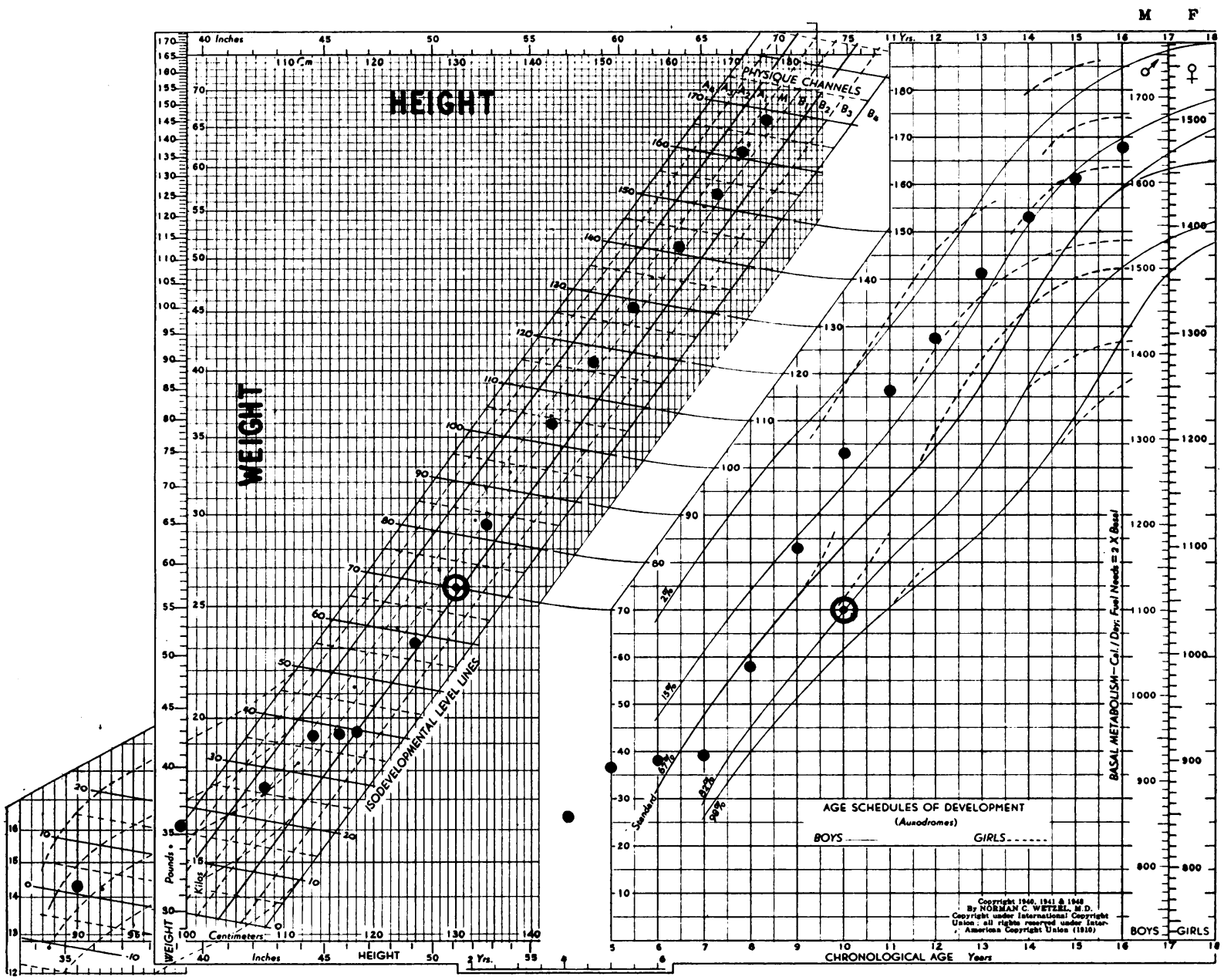

[By courtesy of Dr. Wetzel and N.E.A. Service Inc., Cleveland.

Fig. 7.-Wetzel grid. The solid dots represent the growth of the same child as illustrated in Fig. 4A and B.

skewed or heteroscedastic weight arrays; and whether or not these are produced we do not know. But again it suffers from the disability of distance standards used as though they were velocity ones. Over the straight line portion the standard lays down that increment $\log$ weight $=k$. increment log height, a velocity regression of a similar nature to Fig. 4E. But no figure for $\sigma$ est is given, and no data as to the distribution of increments of log weight for given increments of log height; weight increments are usually somewhat positively skewed, but one's suspicion is that taking logarithms may overcorrect. An apparently empirical tolerance limit of $\frac{1}{2}$ channel deviation in 10 isodevelopmental levels is mentioned, but its source is not clear and it assumes quite uncritically homoscedasticity of arrays from age 6 on and, presumably, since deviations in either direction are subject to the same rule, a Gaussian distribution in arrays. What has been said above about any regression standard for weight on height not necessarily distinguishing abnormals if the disturbing influence affects both measurements proportionately applies, of course, also to the grid. Apart from these points, however, the grid does seem a neat way of recording weight, height and weightfor-height data so long as the user understands clearly its simplicity of approach and the limitations to the information it gives. Various tests of its use in practice have been made and various opinions passed (Bruch, 1942; Simmons and Greulich, 1943; Stuart and Meredith, 1946; Dreizen, Mann and Spies, 1948; Mann, Dreizen, Pyle, and Spies, 1948; 
Krogman, 1950). It does seem to me that the grid has little or no advantage over percentile graphs for height and weight combined with a weight-on-height regression standard, and it cannot compare in usefulness and accuracy with the simultaneous use of distance and velocity charts as outlined in Fig. 5 and discussed in the following section.

Other Standards. Correnti (1948-49) has recently published a weight-for-height auxogram, which has a much firmer biometrical foundation than the Wetzel grid, and seems in many respects preferable to it. The auxogram is a height-on-weight regression, the variables untransformed, the regression therefore curvilinear. At each year of age the means of height and weight are plotted, and around them an ellipse, containing some particular percentage (say $90^{\circ}$ ) of the total children of that age. Those within the ellipses are normal, those without are not. The ellipses are calculated on the assumption of a joint Gaussian distribution of height and weight for each age, and this is certainly a questionable assumption. Also the auxogram is subject to the criticism of distance standards being used for judging velocity.

TUXFORD`s INDEX. Another distance standard recommended for use as a velocity one is Tuxford's (1939, 1942) index (Campbell and Weir, 1948). Tuxford uses the ratio weight/height rather than a regression equation for comparing the two measurements, and his method essentially gives simply the mean weight height at each age from 5 to 16 for boys and girls. He found, however, that this ratio decreases approximately in a straight line with increasing age, so that instead of giving a distance table for weight/height at each age, a linear correction for age brings back the mean weight/height to very nearly $1 \cdot 00$. Tuxford's index (1942 edition) is founded on the 1938 London County Council data given by Menzies (1940), and for boys is

and for girls

$$
\text { T.I. }=\begin{aligned}
& \text { Wt. (kg.) } \\
& \text { Ht. (cm.) }
\end{aligned} \times \frac{335 \text {-age in months }}{48}
$$

$$
\text { T.I. }=\frac{\text { Wt. }(\mathrm{kg} .)}{\mathrm{Ht} .(\mathrm{cm} .)} \times \frac{308-\text { age in months }}{42}
$$

The mean of the index is not exactly 1.00 for each age in these data, but comes fairly close to it except for boys at age 14 where T.I. $=0.987$, and for girls aged 5. No standard deviation or percentile spread at any age is given, so that even as a distance standard the index is impressionistic only. Tuxford says that values below 0.95 deserve investigation, but the basis of this statement is not clear, and it seems to assume that the scatter of weight/height is the same at each age, which certainly cannot be the case. If a value of 0.95 is a warning at adolescence, then something much nearer unity should be the warning at, say, 6 years. Even if we had percentile limits, however, one would still be somewhat uncertain how precisely to interpret an abnormal ratio: ratios may look simple but they are biometrically a bit complicated and present to the statistically unsophisticated several pitfalls, some of which I have discussed elsewhere (Tanner, 1949b).

Tuxford also recommends using his index to judge velocity, and this in very much the same way as the channel system in Wetzel's grid. In health the Tuxford index is assumed to be constant from year to year, this being the equivalent of straight progression up the channel. This time the standard is weight/height increment $=-c$. age increment, but again no figure for $\sigma$ est is given and no data as to the distribution of weight/height increments for given age increments. Tuxford suggests that a change of index of 0.02 over a year should be regarded with suspicion, but whether this applies equally at all ages is not clear. It is interesting to compare the use of Tuxford's index and the Wetzel grid in one of the articles (Wetzel, 1942) in which Wetzel first fully introduced his system. Wetzel criticizes the Tuxford index and alleges that it does not show that the particular boy used as an example is retarded in growth progress, whereas the grid does. Unfortunately for his thesis, however, Wetzel uses Tuxford's index quite wrongly, applying the empirical distance criterion where he should apply the velocity one; used properly the index shows the falling weight-for-height at exactly the same time and with the same force as does Wetzel's channel system. Neither, however, can be considered very satisfactory.

Velocity Regression Standard. There have so far been very few attempts to construct a proper velocity regression standard of the sort shown in Fig. 5F. Bransby (1945) has suggested and tentatively used a standard for weight attained after so many years at school for height increment during residence at the school. Further subdivisions were made by age at entry to school and weight at entry. Thus a standard curve of weight attained for given height increment was provided for each $2 \mathrm{lb}$. weight group and each year of age at school entry. In other words, the 10-year-old $62 \mathrm{lb}$. child had a standard curve covering the rest of his school career, the 10-year-old $64 \mathrm{lb}$. child another, and the 11-year-old $64 \mathrm{lb}$. child a third. The material was insufficient for percentile limits to be accurately laid down, but the approach is an interesting one and might repay more extensive study. This method combines velocity in one measurement with distance in another, a perfectly simple and useful possibility 
in regression standards. Also two values of the same anthropometric measurement at different ages can be used if desired; for example, in constructing a standard for weight at age 1 or 2 or more by regression on birth weight (Asher, 1950; Illingworth, 1950) or in comparing the growth of children of different economic groups (Greenberg and Bryan, 1951). Bransby and Hammond (1950) are currently considering whether standards of this general sort for subcutaneous tissue change over fairly short periods would have screening value for the assessment of malnutrition. Stuart and Reed (1951) have dealt with the same problem by fitting straight lines for each individual to the growth in volume of subcutaneous tissue by radiograph of the calf over the age range 1 to 6 years: the fit is good but the residual variance about the line is significant, which is not the case for muscle and bone lines. The causes of a significant departure from the line are then sought. This method begins to approach a test of hypothesis, D above (page 14), of growth being normal over a whole range of years, and may turn out to be a most powerful technique.

\section{Suggested Form for Combined Distance, Velocity and Standard-score Difference Standards}

It is possible that a small simplification of the regression type of standards could be made along lines rather vaguely suggested elsewhere (Tanner, 1950, 1951a) and if this simplification is combined with both velocity and distance standards an overall test for abnormality more adequate than any so far available might perhaps be achieved. The use of the distance and velocity standards as suggested in Fig. 5A, B, C, D, implies finding first of all the standard deviation score or percentile for the two measurements, let us say height and weight, and it is easy to see that the difference between these scores for the two measurements relates height and weight to one another in the same sort of way as does the regression equation. If $X \mathrm{~cm}$. is the height of a child age 6 say, $\bar{x} \mathrm{~cm}$. the average height of 6 -year-olds, and $\sigma_{x}$ the standard deviation of 6-year-olds, then the score $z=X-\bar{x}$ is called the

$$
\sigma_{\mathbf{x}}
$$

standard score for the child. All standard scores have a mean of zero and a standard deviation of unity. The mean difference of the two standard scores will be zero, and the standard deviation of

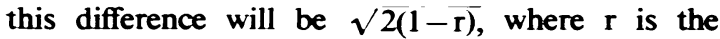
coefficient of correlation between the two variables concerned. Thus if a child has standard scores for height and weight of +1.2 and -0.8 respectively. his standard-score difference is

$$
\mathrm{z}_{\mathrm{wt}}-\mathrm{zht}_{\mathrm{ht}}=-0 \cdot 8-1 \cdot 2=-2 \cdot 0
$$

The test for whether such a difference could have arisen in a normal healthy population or whether it indicates that the child is abnormally underweight for height is made by comparing this height-difference with its standard deviation. If the correlation between height and weight at the age considered is $\mathbf{0 . 7 5}$, then the standard deviation of the height-weight difference is $\sqrt{2(1-\cdot 75)}=$ 0.7 units. The ratio of height-weight difference to its standard deviation is therefore $-2 \cdot 0=-3 \cdot 0$, $0 \cdot 7$

which is far out beyond even the first percentile (which it will be recalled is at $2 \cdot 3 \sigma$ ) and undoubtedly signifies abnormally low weight for height.

This procedure seems to me rather simpler than the usual regression computation, and gives the same information. Admittedly the example above is badly chosen, in that the distribution of the $Y$ variate should be Gaussian for each broad division of $\mathrm{X}$, and these distributions should have the same standard deviation. However, it should not be too difficult to allow for skewness of weight arrays either by the use of tables transforming weight, as suggested in the footnote to Fig. 8 , or by adjustment

GROWTH PROGRESS CHART

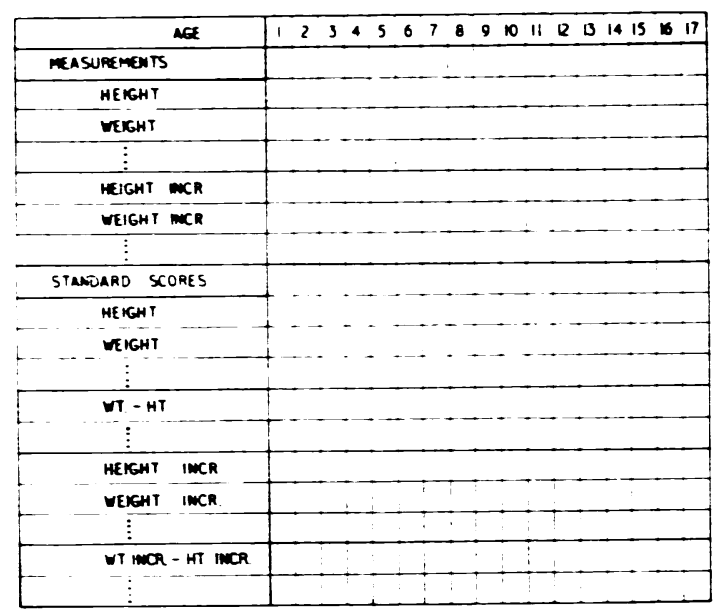

FIG. 8.-Increment 1-2 years entered under 2 year column. Ring in black standard scores coming below 5 th or above 95 th percentile; in red scores coming below 1 st or above 99 th percentile.

The chart is accompanied by three tables:

A. Pearl's tables to convert increments to per year.

B. Tables for turning measurements to standard scores; incorporating transformation for non-normally distributed measurements.

C. Tables for percentiles corresponding to standard score differences for each pair of measurements at each age if necessary. 
of the final value corresponding to the figure of -3.0 in the example above. If the within-age type of regression (see page 24 above) is wanted it would be necessary to give a table of correlation coefficients

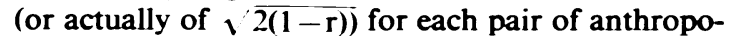
metric dimensions at each year of age, and this is the preferable form if the regression is at all curvilinear. If the irrespective-of-age regression is required, then the standard scores are obtained by reference to the mean and standard deviation of the measurements at all ages, and the correlation is the overall correlation for the whole age range. However, one of the advantages of standards couched in this way is that when the regression is rectilinear, the conditions for the two types of regression tests to be identical, as outlined above on page 25 , are met if the correlations at each age are the same. For the height-weight correlation the published figures show little trend during growth up to the last two or three years (Wilson, 1935: Simmons, 1944). It seems that a figure of about 0.75 would cover adequately both boys and girls, the former for age 1 or less to age 16 , the latter from 1 or less to age 13 . The correlation for weight increment-height increment is about 0.40 from 2 till 12 (Simmons and Todd, 1938).

The form of the report suggested is given in Fig. 8: the upper block contains the actual figures for weight and height and any other measurements taken, at each age, and the figures for their velocity. The 1 to 2 year velocity is placed in the 2 -year-old column and all velocities are given as so much per year since the intervals between successive examinations are inevitably different on different occasions: for example, 360 days one time but 380 the next. Pearl's tables (1940) giving the proportion of a year lying between any two dates can be used to facilitate the conversion. The lower block in Fig. 8 contains the standard scores, obtained by reference to the standard tables used, that is tables embodying the lines of Fig. 5A, B, $C, D$. One new item appears here; this is weight height. one standard score being subtracted from the other. Reference to a third table completes the job: in this are listed the percentile points corresponding to the standard scores and the standard score difference for each year, the table being constructed on the basis of the distribution of the standardizing data. If the correlations between two measurements are equal each year then this system is equivalent to either regression standard: if not. then it is equivalent to the within-age type only: but it could be extended to the irrespective-of-age type by reference to another table wherein standard scores for weights appropriate to various height groups were entered.
The construction of British standards of this sort would probably be immediately possible for height and weight. The distance data have been discussed above and though, so far I am aware, no means and percentiles for height or weight increments have yet been published in this country, several local authorities and secondary schools must have the data in their files. Pending their production, however, it might prove possible to use the American velocity data after a little experience had been gained in their interpretation, or to use, as a temporary expedient, British mean increments obtained crosssectionally with percentile limits from the American data.

The interpretation of such standards is subject to the uncertainties discussed above, and it seems at present impossible to suggest anything more positive than caution in using multiple standard scores, or if this is impossible, reliance on one sole item such as weight increment standard score minus height increment standard score, or whichever is found to work best in practice.

\section{Standards for Maturity}

The advent of the adolescent spurt in growth bedevils all the standards so far discussed. The reason for this is that there is a wide spread between individuals in the time at which the spurt starts. and so, with some children suddenly speeding up tremendously and others not at all, the scatter of the normal increases greatly. Consequently our standards, though perfectly valid still, become far less potent for detecting abnormality. We need to combine them with some index of whether adolescence has started or not.

In longitudinal growth studies several ways have been used for indicating the relation of a child at any time to his adolescent spurt. For girls menarcheal age is an excellent indicator, a given girl being scored so many months before or after the menarche: the time of maximal velocity in height has also been most effectively used (Shuttleworth, 1937, 1938, 1939). Neither of these are available, however, except in retrospect; one cannot tell how much before the menarche a girl is until, obviously, she has reached it. In the circumstances considered in this paper two, or perhaps three, methods are available: these are the rating of secondary sex character development, the skeletal (wrist and hand) development, and, possibly, tooth eruption development.

Standards for secondary sex character (S.S.C.) development in the case of boys have been given in detail by Greulich and his associates (Greulich. Dorfman, Catchpole, Solomon and Culotta. 1942) Five stages are described, stage 1 being pre-pubertal, stage 2 beginning growth of testes, penis, pubic hair, 
stage 3 a further development of testes, penis and pubic hair and often the beginning of facial hair, stage 4 further development again, with face hair definite and axillary hair beginning, and stage 5 near adult. These stages are, of course, far more fully described and illustrated by Greulich, so that a scaling on a rapid clinical examination should be perfectly feasible. For girls, similar scales for breasts and pubic hair separately have been illustrated by Reynolds and Wines (1948), and a rating combining the two eharacters would be simple to arrange. Since the breast and pubic hair begin developing about two years before the menarche on an average, S.S.C. ratings cover just the period when the adolescent spurt is maximal. (The menarche occurs shortly after the point of maximal velocity in stature.)

Several possible ways of incorporating these ratings into growth standards suggest themselves. First, simple standards for the time at which each stage occurs and the normal limits of this should be established; second, height and weight, and indeed all anthropometric standards during puberty, should be couched in terms of S.S.C. maturity group as well as, or instead of, chronological age; thirdly, regression standards using simply S.S.C. maturity ratings as one variable could be constructed; fourthly, a S.S.C. age could be developed in exactly the same way as skeletal age below.

Skeletal (Wrist-hand) Maturity. These standards go a little further. The maturation of the skeleton can be followed by $x$-rays and judged by whether such and such an epiphysis has appeared, whether another has closed, what shape a third has and so on. This skeletal maturation does not follow chronological age exactly, and especially at puberty the two part company. If the boy is an early maturer, his adolescent spurt in height and other anatomical and physiological measurements comes early, his secondary sex characters develop early and his bone appearances hasten to adulthood. Thus skeletal radiographs enable one to judge how far along in adolescence is a given child (and are quite closely related to S.S.C. groups in this), and they also, stretching back to birth, enable one to rate as mature beyond his years a child of any age whatsoever. The technique at present used is to take a radiograph of the left hand and wrist, a simple matter that can be very satisfactorily done with a small, portable dental machine. A set of standards is then consulted, the original one due to Todd (1937) having been recently superseded by a new edition from Greulich and Pyle (1950). Skeletal development has from the start been dealt with in the same way as mental age: a given boy " $\mathrm{s}$ radiograph is matched to a particular standard and if that standard represents the development of the average boy of age $10 \frac{1}{2}$, one lists the boy's skeletal age as $10 \frac{1}{2}$ years. In practice the matching of films with standards demands a certain amount of skill and practice, and unfortunately wrist and hand changes seem to be minimal just at the beginning of puberty, thus tending to make the ratings least reliable and finelyspaced just when one wants the information most. The information one does get, however, is very valuable and this technique has deservedly gained a wide reputation for usefulness. Recently, a refinement of it, for use more in special than in general circumstances, perhaps, has been proposed by Pyle and her associates (Pyle, Mann, Dreizen, Kelly, Macy and Spies, 1948). In this, besides the whole appearance of wrist and hand being used to obtain the skeletal age, each individual bone or part in the radiographs is assigned a skeletal age and the range of the most advanced to the least advanced bone is given. This refinement is known. for historical reasons, as the red graph method. Malnutrition and certain other states are believed to increase the variability of maturation in the bones of hand and wrist besides retarding it generally.

The incorporation of skeletal maturity into general standards follows the same lines as that of S.S.C. maturity above (Bayley, 1943; Gray, 1948). It is not yet known to what extent the skeletal ages of American and British children are the same in terms of chronological age. Although the pattern of maturing is probably very similar in both countries. it may well be that the American children on whom the standards are founded are somewhat ahead of the average British child in maturity at any given age. If so, then while the average American child of chronological age $10 \frac{1}{2}$ will have, being average. a skeletal age of $10 \frac{1}{2}$ on the Greulich-Pyle standards. the British average child of $10 \frac{1}{2}$ would have a skeletal age of somewhat less. No British standards are yet available.

Tooth Eruption Development. Tooth eruption development has not as yet been used as a measure of maturation, but there seems no good reason why it should not at least be tried; a measure of tooth age could readily be obtained, it would seem, from the figures in Palmer, Klein and Kramer's paper (1938) on the Hagerstown children or from Hellman's study (1943) in New York (see also Boas, 1933: Bengston. 1935: Doering and Allen. 1942; Meredith, 1946: Hurme, 1948). Tooth age would have its main application in the prepubertal years. and might be of particular interest as girls erupt their teeth somewhat earlier than boys, and this at a time when the sexes are otherwise little distinguished in development. Not much is known at 
present about the relation of tooth eruption maturity to skeletal maturity.

\section{Conclusion}

It would be eminently satisfying if a survey of growth standards such as this started by propounding the statistical principles upon which such standards could be based, went on to list the inevitable results of their application with the appropriate data for use in each circumstance, and wound up with a few simple instructions in the use of a few master tests. But though satisfying, it would be at present wildly inappropriate. We lack as yet any comprehensive theory of the construction of normal standards involving numerous measurements all of which change as time passes, all of which are interrelated and most of which are not quite distributed in Gaussian form; some mathematical background exists (see for example, Box, 1950; Greenhouse and Mantel, 1950; Votaw, Kimball, and Rafferty, 1950; Wilks, 1941) but as yet it is a patchy one. We lack, for the most part, good series of standardizing data, at least for this country. And we are far from any simple and satisfactory general test of healthy growth in the child.

\section{Summary}

The current standards available for assessing whether or not a child is growing normally are presented and reviewed; the theoretical background and the limitations of each one are discussed.

The meaning of the assessment 'abnormal' is discussed, and the view presented that the assessor has in mind two populations, one healthy, the other unhealthy, probably overlapping; limits of normality are arbitrarily fixed for the purpose in hand, arranging inevitably to misclassify a certain proportion of normals as abnormal.

The relative merits of standards couched in percentile and in standard deviation terms are discussed.

The use of velocity or rate-of-growth standards as opposed to distance or size-at-age standards is advocated, and the use of standards for distance as though they were standards for velocity is deprecated.

No British velocity standards are available; the American ones are discussed.

The British and American distance standards available are reviewed and the opinion given that the currently best British height-weight standard data are those of Gore and Palmer for 0 to 5 years and Daley for 5 onwards, both being from London County Council children.

The use of height and weight only is deprecated and the optimal choice of a few measurements is discussed; the proper technique for taking heights and weights is given. No British standards exist for measurements other than height and weight; some of the relevant American data are reviewed.

The combination of two or more measurements into a standard is considered and its two possible regression forms, exemplified by weight-for-heightfor-age and weight-for-height-irrespective-of-age, are presented. The use of each is discussed and the Wetzel grid and Tuxford's index shown to be special examples of such standards.

A suggested system of standards is presented tentatively for experimental trial; various measurements are considered in relation to age, and in relation to each other irrespective of age; both distance and velocity are tested for each measurement. The difficulty in interpreting multiple tests of this sort is stressed.

Standards for maturity, such as skeletal age by hand and wrist radiograph, secondary sex character, age and tooth development age are reviewed.

I wish to thank Mr. M. J. R. Healy for reading the manuscript and suggesting numerous improvements, Professor Henry Barcroft for his interest in and support of this work, and Mr. R. H. Whitehouse for the figures and calculations. I have also greatly benefited from a discussion of these problems with Professor Harold Stuart and Dr. R. B. Reed. Part of the expenses were defrayed from the William Hyde Award of the Research Board for the Correlation of Medical Science and Physical Education.

\section{REFERENCES}

Andersen, M. and Green, W. T. (1948). Amer. J. Dis. Child., 75, 279.

Asher, C. (1950). Proc. R. Soc. Med., 43, 827.

Baldwin, B. T. and Wood, T. D. (1923). Weightheight-age Tables. Tables for boys and girls of school age. American Child Health Association. New York.

(1924). J. Amer. med. Ass., 82, 1. (1925). Amer. J. phys. Anthrop., 8, 1.

Ball, Z. B., Barnes, R. H. and Visscher, M. B. (1947). Amer. J. Physiol., 150, 511.

Bayley, N. (1943). Child Developm., 14, 47.

Bengston, R. G. (1935). Northw. Univ. Bull., 36, No. 8.

Boas, F. (1933). Hum. Biol., 5, 429.

Box, G. E. P. (1950). Biometrics, 6, 362.

Bransby, E. R. (1945). Med. Offr., 74, 29, 37.

- and Hammond, W. H. (1950). Proc. R. Soc. Med., 43, 825 .

Bruch, H. (1942). J. Amer. med. Ass., 118, 1289.

Campbell, F. W. and Weir, J. B. de V. (1948). Brit. J. Nutrit., 2, 119.

Correnti, V. (1948-49). Riv. Anthrop., 36, 120. Reprinted in English translation in Yearbook of Physical Anthropology, Vol. 5, 1949. Viking Fund, New York. 1951.

Count, E. W. (1942). Hum. Biol., 14, 143.

Daley, A. (1950). Report on the Heights and Weights of School Pupils in the County of London in 1949. London. L.C.C.

Dearborn, W. F. and Rothney, J. W. M. (1938). Growth, 2, 197. 
Doering, C. R. and Allen, M. F. (1942). Child Developm., 13, 113.

Dreizen, S., Mann, A. W. and Spies, T. D. (1948). Lancet, 1, 175.

Faber, H. K. (1929). Amer. J. Dis. Child., 38, 758.

Fleming, R. M. (1933). Spec. Rep. Ser. Med. Res. Coun. No. 190.

Franzen, R. (1929). 'Physical measures of growth and nutrition.' American Child Health Association. New York.

Gore, A. T. and Palmer, W. T. (1949). Lancet, 1, 385.

Gray, H. (1948). Child. Developm., 19, 167.

- and Ayres, J. G. (1931). 'Growth in private school children.' Univ. of Chicago Press.

Greenberg, B. G. and Bryan, A. A. (1951). Hum. Biol., 23, 160 .

Greenhouse, S. W. and Mantel, N. (1950). Biometrics, $6,399$.

Greulich, W. W., Dorfman, R. I., Catchpole, H. R., Solomon, C. I. and Culotta, C. S. (1942). Monogr. Soc. Res. Child Developm., 7, No. 3.

- and Pyle, S. I. (1950). 'Radiographic atlas of skeletal development of the hand and wrist.' Stanford Univ. Press. California.

Hellman, M. (1943). Amer. J. Orthodonts., 29, 507.

Holt, L. E. and McIntosh, R. (1940). Holt's 'Diseases of Infancy and Childhood,' 11th ed. New York.

Hopkins, J. W. (1947). Hum. Biol., 19, 68.

Hurme, V. O. (1948). Child Developm., 19, 213.

Illingworth, R. S. (1950). Brit. med. J., 1, 96.

Krogman, W. M. (1950). Monogr. Soc. Res. Child Developm., 13, No. 3.

Lombard, O. M. (1950). Child Developm., 21, 229.

Mann, A. W., Dreizen, S., Pyle, S. I. and Spies, T. D. (1948). J. Pediat., 32, 137.

Maresh, M. (1943). Amer. J. Dis. Child., 66, 227.

Massler, M. and Suher, T. (1951). Child Developm., 22, 75 .

Menzies, F. (1940). 'Average heights and weights of elementary school children in the County of London in 1938.' London County Council.

Meredith, H. V. (1946). J. Dent. Res., $25,43$.

(1949). Amer. J. Publ. Hlth., 39, 878.

- and Meredith, E. M. (1950). Child Developm., 21, 141.

- and Stuart, H. C. (1947). Amer. J. Publ. Hlth., 37, 1435.

Mitchell, H. H. (1932). Hum. Biol., 4, 469.

McCloy, C. H. (1936). Univ. Iowa Stud. Child Welf., 12, No. 2, 126.

(1938). Ibid., 15, No. 2, 260.

O'Brien, R., Girshick, M. A. and Hunt, E. P. (1941). 'Body measurements of American Boys and Girls for Garment and Pattern Construction.' U.S. Dept. Agric. Misc. Publ. No. 366.

Palmer, C. E., Kawakami, R. and Reed, L. J. (1937). Child Developm., 8, 47.

- Klein, H. and Kramer, M. (1938). Growth, 2, 149.

and Reed, L. J. (1935). Hum. Biol., 7, 319.
Pearl, R. (1940). 'Introduction to Medical Biometry and Statistics,' 3rd ed. Philadelphia.

Pyle, S. I., Mann, A. W., Dreizen, S., Kelly, H. J., Macy, I. G. and Spies, T. D. (1948). J. Pediat., 32, 125.

Pryor, H. B. (1936). 'Width-weight Tables for Boys and Girls from 1-16 Years; Men and Women from 17-24 Years.' Stanford. (1941). Amer. J. Dis. Child., 61, 300.

Reynolds, E. L. (1948). Anat. Rec., 100, 621. and Grote P. (1948). Ibid., 102, 45.

- and Wines, J. V. (1948). Amer. J. Dis. Child., 75, 329.

Robinow, M. (1942). Child Developm., 13, 159.

Shuttleworth, F. K. (1934). Ibid., 5, 89. (1937). Monogr. Soc. Res. Child Developm., 2. No. 5 . (1938). Ibid., 3, No. 5.

- (1939). Ibid., 4, No. 3.

Simmons, K. (1944). Ibid., 9, No. 1.

- and Greulich, W. W. (1943). J. Pediat., 22, 518. and Todd, T. W. (1938). Growth, 2, 93.

Smith, C. A. B. (1947). Ann. Eugen., Camb., 13, 272.

Sontag, L. W. and Reynolds, E. L. (1945). J. Pediat., $26,327$.

Stuart, H. C. (1948). Discussion at Viking Fund Summer Seminar in Physical Anthropology, 1948. New York. Reported in Yearbook of Physical Anthropology, 1947, Vol. 3, p. 13. (Publ. 1948.) and Kuhlmann, D. (1942). J. Pediat., 20, 424. and Meredith, H. V. (1946). Amer. J. Publ. Hlth., 36, 1365.

and Reed, R. B. (1951). Ibid., 41, 85.

- and Sobel, E. H. (1946). J. Pediat., 28, 637.

Sutcliffe, A. and Canham, J. W. (1950). "The Heights and Weights of Boys and Girls.' London.

Tanner, J. M. (1948). Yearbook of Physical Anthropology, 1947. Vol. 3, p. 28. New York. Viking Fund Inc.

(1949a). Lancet, 1, 663.

(1949b). J. appl. Physiol., 2, 1.

(1949c). J. clin. Invest., 28, 567.

(1950). Abstr. Proc. XVIII. Physiol. Congr.

(1951a). Hum. Biol., 23, 93.

(1951b). Lancet, 1, 574.

Todd, T. W. (1937). "Atlas of Skeletal Maturation. Part I-Hand.' St. Louis.

Tuxford, A. W. (1939). J. Hyg., Camb., 39, 203. (1942). Ibid., 42, 549.

Vickers, V. S. and Stuart, H. C. (1943). J. Pediat., 22, 155 .

Votaw, D. F., Kimball, A. W. and Rafferty, J. A. (1950). Biometrics, 6, 259.

Wetzel, N. C. (1941). J. Amer. med. Ass., 116, 1187.

(1943). J. Pediat., 22, 82, 208, 329.

(1944). In 'Medical Physics,' ed. O. Glasser, Vol. 1, p. 513 . Chicago.

Wilkins, L. (1950). "The diagnosis and treatment of endocrine disorders in childhood and adolescence' Springfield, Illinois.

Wilks, S. S. (1941). Ann. math. Statist., 12, 91.

Wilson, E. B. (1935). Proc. nat. Acad. Sci., Wash., 21, 633 . 